\title{
Shape memory materials and 4D printing in pharmaceutics
}

Alice Melocchi, Marco Uboldi, Matteo Cerea, Anastasia Foppoli, Alessandra Maroni, Saliha Moutaharrik, Luca Palugan, Lucia Zema*, Andrea Gazzaniga

Sezione di Tecnologia e Legislazione Farmaceutiche "Maria Edvige Sangalli", Dipartimento di Scienze Farmaceutiche, Università degli Studi di Milano, via Giuseppe Colombo 71, 20133, Milano, Italy.

*Corresponding author: lucia.zema@unimi.it, +390250324654

Keywords: shape memory alloys, shape memory polymers, shape memory effect, 3D printing, 4D printing, drug delivery systems, controlled release. 


$\begin{array}{ll} & \text { Abstract } \\ 1 & \text { Shape memory materials (SMMs), including alloys and polymers, can be programmed into a } \\ 2 & \\ 4 & \text { temporary configuration and then recover the original shape in which they were processed in response } \\ 5 & \\ 6 & \text { to a triggering external stimulus (e.g. change in temperature or pH, contact with water). For this } \\ 7 & \\ 8 & \text { behavior, SMMs are currently raising a lot of attention in the pharmaceutical field where they could } \\ 9 & \\ 10 & \\ 11 & \text { bring about important innovations in the current treatments. 4D printing involves processing of } \\ 12 & \\ 13 & \text { SMMs by } 3 \mathrm{D} \text { printing, thus adding shape evolution over time to the already numerous customization } \\ 14 & \\ 15 & \\ 16 & \text { possibilities of this new manufacturing technology. SMM-based drug delivery systems (DDSs) } \\ 17 & \\ 18 & \text { proposed in the scientific literature were here reviewed and classified according to the target pursued } \\ 19 & \\ 20 & \\ 21 & \text { through the shape recovery process. Administration route, therapeutic goal, temporary and original } \\ 22 & \\ 23 & \text { shape, triggering stimulus, main innovation features and possible room for improvement of the DDSs } \\ 24 & \\ 25 & \\ 26 & \text { were especially highlighted. } \\ 27 & \\ 28\end{array}$




\section{Contents:}

1. Introduction and aim of the review

1.1 Shape memory alloys (SMAs)

1.1.1 Mechanism of shape recovery

1.1.2 Main applications and characterization studies

1.2 Shape memory polymers (SMPs)

1.2.1 Mechanism of shape recovery

1.2.2 Main applications and characterization studies

1.2.3 $4 \mathrm{D}$ printing

2. Drug delivery systems based on SMMs

2.1 Shape recovery for reaching the target area

2.2 Shape recovery for enabling retention in the target area

2.2.1 Implants/scaffolds

2.2.2 Stents

2.2.3 Intra-organ systems

2.2.4 Systems for wound treatment

2.3 Shape recovery for ensuring removal from the target area

2.4 Shape recovery for triggering drug release

3. Conclusions

References 


\section{Introduction and aim of the review}

Versatility currently represents a key concept for R\&D in many industrial fields and increasing attention is driven towards materials showing advanced functionalities that make them suitable for a range of applications [1-2]. In this respect, shape memory materials (SMMs), generally referred to as smart or intelligent materials, started to raise a lot of interest in different areas [3-5]. They are supposed to dynamically respond and adapt themselves to an external stimulus - typically a variation in the environment - thus performing their functions according to the changes undergone [6-8]. The actual ability to control the modifications undertaken is a key factor in the definition of smart materials. In particular, SMMs are able to change their shape in a predefined way upon appropriate stimulation. They can be forced, by application of an external stress, to take on a secondary/temporary shape, starting from the permanent/original one they were processed into. This is called programming step or shape-memory creation process. The temporary shape is maintained, even after the stress removal, until the material is exposed to the specific non-mechanical stimulus (e.g. direct heating, indirect heating through the application of electromagnetic fields or light, contact with water, change in the $\mathrm{pH}$ or ion composition of the liquid environment) able to induce the so-called shape memory behavior or effect, i.e. the recovery of the original shape. In other words, SMMs have the ability to temporarily store the mechanical stress applied during programming and undergo, only upon application of a suitable trigger, the pre-defined mechanical actuation when relieving this stress. Notably, the movement occurring during recovery reverses the mechanical deformation that has led to the temporary shape. For these peculiar characteristics, literature refers to SMMs as materials able to remember the memorized shape.

Although the identification and the first knowledge of SMMs can be traced back to the 1940s, their diffusion and the strongest impetus for their use came at the end of the 1990s [9]. In view of their broad applicability potential and of the possibility of using them for targets hardly achievable in other ways, SMMs started to be employed in automotive, packaging, electronic and textile industries. Indeed, product design phase was revolutionized by SMMs, giving to developers the possibility of 
working on two different geometries of the same product at the same time and on how the transition

from the former to the latter would happen [10]. Later on, SMMs spread out also towards more sophisticated fields such aerospace and biomedicine [1,5,11]. As a consequence, the market associated with these materials and the relevant application is expected to reach $\$ 1.84 \mathrm{~B}$ by the end of year 2026, with a growth of approximately $25 \%$ per year from 2019 to 2026 and with the AsiaPacific region highlighting the fastest rate $[12,13]$.

Only more recently, SMMs were also considered in the pharmaceutical area, particularly at the research level, given their potential for innovating current therapeutic strategies. The aim of the present review is to critically discuss the applications proposed so far in the primary scientific literature describing the use of SMMs in this new field. More into detail, articles focused on drug products, mainly drug delivery systems (DDSs), were considered. Conversely, drug-free items showing shape memory response, such as medical devices and scaffolds, were deliberately excluded. Due to the complexity of the subject investigated, the research articles here reviewed often represented a joint work from experts of different fields, such as chemical and mechanical engineering, chemistry, biology, medicine and pharmaceutical technology.

Applications relying on both shape memory alloys (SMAs) and shape memory polymers (SMPs) were analyzed, and a classification based on the objective pursued through the recovery of the original shape was proposed. Particularly, shape recovery was employed to $i$ ) reach the site of drug delivery, ii) enable prolonged retention in situ after minimally invasive administration, iii) ensure removal from the target site, and $i v$ ) trigger drug release. Considering the real novelty of such applications, studies mainly aimed at in-depth investigating the shape memory behavior for sole characterization purposes were also reviewed. With reference to the definition of smart materials, in this manuscript only DDSs based on SMPs and SMAs were reviewed, for which well-defined and recognizable original and temporary shapes were described, the latter obtained following a specific programming step. On the contrary, the numerous smart applications based on hydrogels involving a generic gel-sol transition, 
which was not associated with well-defined temporary and original shapes and relied on a nonprogrammed shape shifting, have been purposely ruled out.

\subsection{Shape memory alloys (SMAs)}

In 1951, the shape memory effect of an alloy based on gold and cadmium was observed for the first time by Chang and Read [6,14]. In 1963, Buehler and colleagues described the same phenomenon for nitinol, an equiatomic nickel and titanium alloy. Subsequently, other SMAs were studied, such $\mathrm{Cu}-\mathrm{Zn}-\mathrm{Al}$ and $\mathrm{Fe}-\mathrm{Mn}-\mathrm{Si}$ based materials. However, nitinol probably remains the main SMA investigated in the biomedical field for its unique characteristics, such as superelasticity, good combination of high strength and low elastic module, high corrosion resistance as well as biocompatibility and non-ferromagnetic properties, which provide a clear image during magnetic resonance and make it particularly suitable for biomedical applications [15,16]. Recently, a few attempts have also been proposed to attain surface modifications of nitinol-based materials thus mitigating the risks associated with the presence of a potentially toxic, allergenic and carcinogenic component, i.e. nickel [17-20].

Starting from nitinol as such or in combination with other materials, various shapes and sizes can be fabricated: thin films, fibers, particles and porous matrices. Nitinol based-ternary alloys have also been proposed to meet particular needs, such as to provide the material with intrinsic antibacterial activity (e.g. Ni-Ti-Cu, Ni-Ti-Ag) $[15,21,22]$. However, the associated fluctuations in the nitinol stoichiometry were shown to have strong impact on the properties of the resulting SMA, such as changing the relevant activation temperature [6].

\subsubsection{Mechanism of shape recovery}

From the chemical point of view, SMAs and particularly nitinol occur in two solid phases, each with a different crystal structure and peculiar properties [3,6,23-28]. The austenite phase, predominant at higher temperatures, generally exhibits a cubic crystal structure, while the martensite phase is 
characterized by tetragonal, orthorhombic or monoclinic crystal structure, depending on the alloy composition. Moreover, each martensitic crystal can exhibit a different orientation, called a variant, so that a twinned martensite, composed of a combination of self-accommodated martensitic variants, and a detwinned martensite, in which a specific variant is dominant, can be recognized. The transformation from one crystal structure to the other (i.e. martensitic transformation) is the basis for the shape memory effect. More into detail, austenite, under no load conditions and upon cooling, begins to transform into twinned martensite at the martensitic start temperature $\left(\mathrm{M}_{\mathrm{s}}\right)$ and complete the transformation at the martensitic finish temperature $\left(\mathrm{M}_{\mathrm{f}}\right)$. During heating, the reverse transformation takes place, initiating at the austenitic start temperature $\left(A_{s}\right)$ and ending at the austenitic finish temperature $\left(\mathrm{A}_{\mathrm{f}}\right)$. If a mechanical stress is applied to the material in the twinned martensitic phase at low temperatures, a detwinning phenomenon occurs with the reorientation of a certain number of variants. Such a process results in a macroscopic shape change and the configuration attained upon deformation can be retained also when the load is removed. This behavior makes it possible to program the SMA temporary shape. Upon heating above $A_{f}$, the detwinned martensite will go back to austenite phase, thus leading to complete shape recovery. Cooling back to a temperature below $\mathrm{M}_{\mathrm{f}}$ will result in the formation of twinned martensite with no associated shape change. The minimum stress required for starting the detwinning process is named detwinning start stress $\left(\sigma_{\mathrm{s}}\right)$, while the stress level corresponding to complete detwinning of martensite is recognized as the detwinning finish stress $\left(\sigma_{\mathrm{f}}\right)$. When the material in the austenitic phase is cooled upon a mechanical load greater than $\sigma_{\mathrm{s}}$, the phase transformation can cause the direct formation of detwinned martensite, thus producing a shape change. On the other hand, reheating the material would determine the relevant shape recovery while the load is still applied. Overall, the transformation temperatures increase with an increase in the magnitude of the load. Stress-free cooling of austenite below the $\mathrm{M}_{\mathrm{s}}$ and $\mathrm{M}_{\mathrm{f}}$ results in the formation of twinned martensite. When the latter is subjected to an applied stress that exceeds $\sigma_{\mathrm{s}}$, a reorientation process is initiated, with the growing of favorably oriented martensitic variants. The detwinning process is completed at $\sigma_{\mathrm{f}}$ and is maintained also in the absence of load. 
Upon heating with no stress, from $A_{s}$ to $A_{f}$ the shape recovery occurs and only the parent austenitic phase remains. Subsequent cooling to martensite will result in the formation of self-accommodated twinned martensitic variants with no associated shape change, and the whole cycle of the shape memory could be repeated. To summarize, a SMA exhibits the shape memory effect when it is deformed in the twinned martensitic phase and then unloaded while at a temperature below $\mathrm{A}_{\mathrm{s}}$. Upon heating above $A_{f}$, it will recover its original shape, by going back to the parent austenitic phase.

The phase transformation of SMAs can be triggered not only by temperature (i.e. shape memory effect) but also by applying a sufficiently high mechanical load to the material in its austenitic phase, leading from austenite to fully detwinned martensite. When the stress is released at temperatures above $A_{f}$, the crystal form returns to the austenite phase and the material regains the more stable initial micro-/macroscopic configuration. This phenomenon is known as superelasticity, and it leads to an immediate shape change on unloading, which cannot be controlled nor programmed. In the case of nitinol, such a phenomenon typically occurs at room temperature.

\subsubsection{Main applications and characterization studies}

Since its discovery, many commercial applications of nitinol were proposed, but only in the 1990s this material made its commercial breakthrough in the biomedical field [26,29]. In this respect, various devices have been designed, such as archwires, drills for root canal surgery, spinal vertebra spacers, artificial bone implants, tools for microsurgery such as a cardiovascular atrial septal occlusion device, filters for removing blood clots, and the so-called self-expanding stents [30-33]. The latter have been investigated for allowing expansion of esophagus, biliary duct, trachea, bronchi, ureters and urethra. However, their blockbuster is probably represented by the vascular application. Traditionally, vascular stents were made of stainless steel. They were inserted in the human body through a catheter and were expanded in situ to the size of the artery by an inflatable balloon. The use of self-expanding superelastic nitinol stents allowed to overcome the limitations typical of stainless steel stents, such as the partial fit loose associated with the elastic unloading and damages 
of vessels resulting from over-expansion, while improving adaptability to different anatomical characteristics. After being constrained, the stent is introduced into the body where the temperature exceeds $A_{s}$. When the external constriction of the catheter is removed, the stent expands to adapt itself to the larger diameter of the vessel due to the above mentioned superelasticity and gently pushes outward on the walls.

When dealing with the applications in the pharmaceutical field, nitinol still turned out to be the main material investigated. Different targets for using its shape recovery capability were identified and will be discussed in Chapter 2. As nitinol can also show a superelastic behavior, the DDSs only relying on such a characteristic were deemed out of the scope of the present review, although they may show similar functionality and therapeutic objectives to those here considered [34-37]. Besides drugcontaining stents showing self-expansion, two of the most significant applications are the Lidocainereleasing intravesical system named LiRIS and a gastroretentive device for long-term tuberculosis treatment developed by Verma and coauthors $[34,38]$. The LiRIS system is an osmotic pump in which a nitinol wire is inserted into a silicon tube also housing a drug containing formulation (e.g. powder, mini-tablets). The nitinol wire has a pretzel-like shape which allows the system to assume a bulky configuration that prevents its emptying from the bladder. However, to accommodate the system inside a catheter for intravesical administration, the nitinol wire was mechanically forced into an elongated shape which was maintained by the constraint. When the stress was released at body temperature, the crystal nitinol returned to the austenite phase and regained the coiled shape in which it was produced.

The gastroretentive systems devised by Verma and colleagues for long-term doxycycline hyclate and isoniazid treatment relied on an analogous working mechanism. It entailed a superelastic nitinol wire, in which pierced drug-containing matrices were inserted, ending with a retainer and a magnet. To increase drug loading and duration of therapy, the length of the wire and the formulation of matrices could be modified. After reaching the stomach through a nasogastric tube, in which the system was 
forced to assume an elongated configuration, the nitinol wire curled back to the cylindrical coil shape, thus preventing the relevant emptying through the pylorus.

Given the wide diffusion of SMAs, ASTM International has published standard test methods to guide experimentation efforts towards the definition of their behavior, especially for $R \& D[6,23,27]$. These may involve differential scanning calorimetry (DSC), thermomechanical testing and the bend test to draw indications about austenite-related temperatures. DSC analyses can be used for highlighting solid phase transformations in SMAs under zero stress and for estimating the key transformation temperatures. Thermomechanical testing performed on wires, dog-bones and tubes mainly involve tensile axial loading, compressive tests and also multiaxial loading. The bend test is performed to gain qualitative information about austenite-related temperatures. In fact, at the beginning of the test, the specimen, in the shape of wire, tube, or strip is deformed at temperature lower than $A_{s}$, causing formation of the detwinned martensite. The temporary shape would then be kept also when the stress is released as the temperature is below $\mathrm{A}_{\mathrm{s}}$. The sample is then slowly heated, monitoring its geometric configuration. The temperature at which the sample begins to recover its original shape would be approximately $A_{s}$, and that at which the recovery process is completed is taken as $A_{f}$.

\subsection{Shape memory polymers (SMPs)}

SMPs, also known as actively moving polymers, exhibit many advantageous features with respect to SMAs, such as being lightweight (density in the $1.13-1.25 \mathrm{~g} \mathrm{~cm}^{-3}$ range versus $6.4-6.5 \mathrm{~g} \mathrm{~cm}^{-3}$ for nitinol) and allowing more marked elongations [7,8,39-40]. Moreover, they can be combined with specific adjuvants (e.g. nanotubes, carbon fibers, magnetic nanoparticles and dyes) in formulations showing new properties [41]. The shape recovery of SMPs can be triggered by a range of external stimuli (e.g. increase in temperature, application of a magnetic field, irradiation, $\mathrm{pH}$ change, contact with water), which could also be applied remotely or wirelessly [7,42-45]. SMPs are generally characterized by a greater shape recovery capability with respect to alloys and they can turn out compatible with a variety of cost-effective manufacturing processes, which have recently started to 
be considered for their potential in the pharmaceutical field (e.g. hot melt extrusion, injection molding, 3D printing) [46-55]. For these reasons, they could be tailored to specific applications. Polynorbornene developed by CdF Chimie Company in 1984 was the first SMP, commercialized under the trade name of Norsorex by the Nippon Zeon Company [6,56]. In the following years, Kurare TP-301 by Kurare Corporation, Asmer by Asahi Company and polyurethane-based SMP developed by Mitsubishi Heavy Industries became available on the market. Initially, SMPs were employed for the fabrication of a range of medical devices, such as self-knotting sutures, scaffolds for tissue engineering and relevant repair, orthodontics, stents, clot removal and aneurysm occlusion devices, systems for cardiac valve repair and occludes for congenital heart diseases [5,40,57]. Later on, they were proposed also in the drug delivery field. In particular, thermo- and chemo-responsive SMPs as well as those based on supramolecular interactions were mainly tested, while applications involving the use of light-responsive polymer are still minor [58-60].

\subsubsection{Mechanism of shape recovery}

The shape recovery behavior of SMPs requires suitable architecture and morphology of the polymeric network, combined with tailored processing and programming steps $[56,57,61,62]$. The typical SMP network is [7,8,62-64]. The netpoints, which are connected by chain segments, are responsible for memorizing the original shape. Indeed, they are not affected by deformation of the material after production (e.g. programming step) and for this reason are generally named as permanent. On the other hand, the chain segments would allow a certain conformational freedom, leading to deformability, which generally increases with length and flexibility of such chains. In particular, flexibility is essential for programming the temporary shape. Therefore, while the secondary shape is stabilized by the temporary fixation of the conformation of chain segments in the deformed shape, the recovery of the original shape is enabled by the entropy-driven recoiling of these segments, as the randomly coiled state represents the most favorable state from the entropic point of view. Such a reversible fixation can be attained either by solidification of the so-called switching domains, which 
are formed by the switching segments, or by formation of further covalent crosslinks (i.e. netpoints) that should be reversible, which means that can be formed and cleaved when needed.

Netpoints responsible for the original shape are generally of chemical (i.e. covalent crosslinks) or physical (i.e. intermolecular interactions) nature. Chemical crosslinks can be created either directly during the synthesis of the SMP or by post-processing methods, adding a radical initiator to the starting materials and inducing relevant crosslinking by radiation (e.g. $\gamma$-radiation, UV light, neutrons). On the other hand, physical interactions are typical of polymers consisting of at least two segregated domains, such as a crystalline and an amorphous phase. In this structure, the domains related to the highest thermal transition temperature (i.e. $\mathrm{T}_{\text {perm }}$ ) are named hard domains and generally show a glass transition temperature $\left(\mathrm{T}_{\mathrm{g}}\right)$ or a melting temperature $\left(\mathrm{T}_{\mathrm{m}}\right)$ much higher than working temperatures, thus acting as physical netpoints in their typical operating conditions. Conversely, the chain segments with the second highest thermal transition (i.e. $\mathrm{T}_{\text {trans }}$ ), which means a lower $\mathrm{T}_{\mathrm{g}}$ or $\mathrm{T}_{\mathrm{m}}$ with respect to that previously mentioned, represent the switching domains. These are responsible for fixing the temporary shape. Fixing can also be promoted by the formation of additional reversible netpoints either of physical or chemical nature. In the former case, the additional netpoints are obtained by solidification of switching domains (e.g. vitrification, crystallization) following cooling. The consequent reduction in molecular mobility allows macroscopic shape fixation. Such netpoints are considered reversible because, by increasing the temperature, the crystals could melt and the glassy domains return to the liquid state. On the other side, reversible chemical crosslinks are generally obtained upon reaction of two functional groups and the resulting chemical bond can be cleaved on demand by exposure to an appropriate stimulus (e.g. cinnamic acid and cinnamyliden acid groups that can undergo a photoreversible reaction when irradiated with light of suitable wavelengths). In this respect, $T_{\text {trans }}$ enabling the reversible solidification of the switching domain can be a melting transition, a liquid crystalline transition and also a glass transition. Notably, chain segments providing the switching domains for the temporary shape and netpoints determining the permanent shape do not need to be covalently connected with each other, as in the case of polymer 
blends. Chemically crosslinked SMPs, in which the temporary shape is fixed by one switching domain, would show marked decrease in the mechanical properties when the temperature exceeds

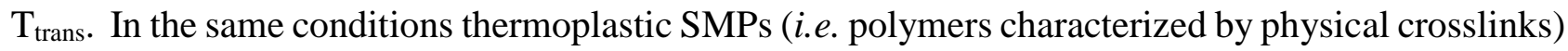
do not show such a drastic change as the crystalline domains, providing the physical cross-links for the original shape, would reinforce the amorphous switching domains. Moreover, although covalent polymeric networks generally exhibit greater capability to fix the temporary shape and recover the original one, thermoplastic SMPs, when actuated, are able to develop much higher stresses. Moreover, they could be subjected to hot processing.

For thermo-responsive SMPs, the temporary shape can generally be programmed by heating the device at a temperature above $\mathrm{T}_{\text {trans }}$ but below $\mathrm{T}_{\text {perm }}$ while applying an external stress. The temporary shape is then fixed by cooling the item below $\mathrm{T}_{\text {trans. }}$ Subsequently, the shape recovery will be triggered only when the temperature will be higher than $\mathrm{T}_{\text {trans }}$ thanks to either a direct or indirect heating process. Besides using a heat source directly in contact with the SMP object, which may also occur on administration at body temperature, indirect heating was attained using laser light, alternating magnetic fields, near-infrared illumination and ultrasound treatment. However, this strategy often requires appropriate formulation, for instance adding to the SMP suitable absorbing dyes, magnetic nanoparticles and other functional excipients.

In the case of chemo-responsive SMPs, the programming step is essentially analogous to that previously described for thermo-responsive polymers [65-67]. However, instead of heating above the switching temperature to start the shape recovery process, the latter is activated by reducing the interaction among macromolecules. This can be attained by softening, swelling or dissolving the socalled transition component (i.e. the part of the polymer able to alter its mobility in response to the triggering external stimulus), thus promoting a reduction in the transition temperature. Focusing on the softening-induced shape memory effect, the recovery of the original shape is driven by the diffusion of solvent molecules into the polymer network. Indeed, the absorbed molecules would act as a plasticizer and decrease the interaction force among macromolecules while promoting the 
mobility of the polymer chains. Overall, this leads to a reduction in the switching temperature with

the recovery of the original shape occurring under isothermal conditions and potentially at room temperature. Such an approach may be applied to fine-tune the transition temperatures of a given polymer network without changing the relevant chemical composition. Moreover, it represents the basis of the water-induced shape memory effect. In pharmaceutical applications, this has the main advantage to reduce the risks of damaging the surrounding tissue due to an excessive increase in temperature needed to trigger the shape switching. Swelling-induced shape memory behavior is typical of hydrogels. The polymer network, upon immersion into an appropriate medium, may progressively hydrate and swell, thus resulting in the formation of a gel. The latter is able to undergo a large deformation, which can be translated in a volume expansion until an equilibrium state for a given environment is reached. At the same time, a reduction in the transition temperature of the polymer could be attained activating the shape recovery process. Finally, shape recovery can be triggered by the dissolution of the transition components of SMPs.

More recently, supramolecular interactions have also emerged as an interesting strategy for the development of novel SMPs with properties not always achievable by the conventional triggering approaches $[59,65,68]$. These materials are based on the incorporation of reversible binding groups into the polymer network, serving as either permanent or temporary netpoints. Indeed, a reversible binding group is a kind of molecular sticker that associates to form dynamic linkages. Depending on the type of sticker, the equilibrium concentration of disassociated groups and the rate of bond exchange can be altered upon appropriate stimulation. For this reason, an ideal reversible binding group should be more stable in the associated state, with slow exchange to establish long-lived netpoints, while exhibiting good reversibility when exposed to the trigger. Reversible binding groups could be either noncovalent or covalent. By way of example, they include hydrogen bonds, ionic interactions, metal coordination, hydrophobic interactions, transesterification and reversible additionfragmentation reactions, as well as disulfide bonds. By using reversible binding groups different goals could be attained, such as decoupling the shape memory effect from the mechanical behavior of the 
polymer and enabling alternative shape memory triggering strategies (e.g. non-thermal switching mechanisms relying on the changes in chemical environment). This way, multiple and tunable shape memory effects could be combined in a single polymer network. Indeed, the relevant shape memory effect can be triggered, step by step, by heating, by contact with a specific solvent and by varying the chemical composition of the fluid in which the material has to perform its function.

\subsubsection{Main applications and characterization studies}

A few decades after the advent of SMPs in the biomedical field, the research interest is currently aimed at $i$ ) testing unusual stimuli to induce the shape-memory effect (e.g. biological stimuli such as interaction with enzymes), ii) achieving more complex shape changes, involving for instance multiple shifts between several temporary shapes, and iii) combining the shape memory behavior with other functions (e.g. biodegradability, electrical conduction, magnetism), to develop so-called multifunctional materials $[62,64,69-72]$.

The level of in-depth knowledge acquired on SMPs over the years has allowed the modification of structural parameters of their molecular architecture, resulting for instance in the modulation of the switching temperature between temporary and original shape $[7,8,57,71]$. This turned out useful for the development of materials specifically tailored to a desired application. Besides the reversible fixation of the temporary shape, the phase transition of the switching domains would determine changes in diffusivity, transparency and mechanical properties of the SMPs. Indeed, the knowledgebased development of new polymers was made possible by appropriate characterization methods employed to study the network on the macroscopic and molecular scale. Also morphological analyses were carried out by fabricating prototypes, mainly by casting.

On the macroscopic scale, the extent to which a deformation can be fixed to give a temporary shape and the recoverability of the permanent shape are of utmost importance and depend on many parameters, such as temperature, environment, kinetics, and type of mechanical deformation in addition to the intrinsic properties of the polymer under investigation $[7,73]$. For this reason, cyclic 
thermomechanical experiments, carried out using a tensile tester equipped with a thermal chamber,

were employed to determine the capability of the switching segment to maintain the programmed shape (i.e. shape fixity ratio) and of the material to memorize and recover the original shape (i.e. shape recovery ratio). The tests involved the programming of the temporary shape, carried out under stress-controlled or strain-controlled conditions, and the recovery of the original one, generally occurring under stress-free conditions. By way of example, a cycle may consist in heating the sample to a temperature higher than $\mathrm{T}_{\text {trans, }}$, but lower than $\mathrm{T}_{\text {perm, }}$, and stretching it to the desired strain. Then the specimen is cooled down below $\mathrm{T}_{\text {trans }}$ under the imposed constant strain, thus fixing the temporary shape. After heating the sample up to $\mathrm{T}_{\text {trans, }}$, shape recovery would occur and the cycle can be repeated. By performing multiple cycles, the effect of processing and storage could also be understood. Also bending tests were in some cases performed, during which the sample heated above $\mathrm{T}_{\text {trans }}$ was bent to a desired curvature and then cooled down to fix the temporary shape. To trigger the shape recovery, the items was then re-heated above $\mathrm{T}_{\text {trans, }}$, and the changes in the deformation curvature were monitored over time. Such tests can be carried out either in air or in contact with suitable aqueous media, depending on the final intended application of the system.

The polymer architecture, intended as netpoints determining the permanent shape and reversible domains determining the temporary one, were in-depth characterized on the molecular/morphological level. Complete testing procedures can be followed to evaluate many different aspects, such as chemical composition and structure, segment lengths, network geometry and relevant morphology, crosslinking density and functionality or physical netpoints, thermal transitions as well as the mechanisms for closure and cleaving of reversible chemical netpoints. In the scientific literature currently available various techniques were proposed: swelling experiments and nuclear magnetic resonance spectroscopy to evaluate crosslink density, differential scanning calorimetry and dynamic mechanical thermal analysis to study the thermal characteristics, transmission or scanning electron microscopy, polarized optical microscopy and scattering methods to investigate the morphology. 
Considering the application of SMPs in the pharmaceutical field, various research works were focused on the chemical structure of the polymer and how to engineer it, for instance to develop multifunctional materials [64,71,74-79]. Indeed, the polymer structure would affect not only the device performance, e.g. in terms of shape memory, dissolution/biodegradation and capability of controlling the release, but also the way the material can be processed to the desired original shape and therefore the compatibility with different drugs to be loaded. The drug itself would represent another key element to take into account. If it is embedded into the SMP matrix, also the loading procedure may have an effect on the overall behavior of the system. Finally, even the characteristics of the physiological environment in which the device is expected to perform (e.g. temperature, $\mathrm{pH}$, presence of ions and proteins) may impact on the SMP behavior. In this respect, an ideal SMP, depending on the functions it has to fulfill in the final DDS, would allow independent tailoring of each of the features it should be provided with [7].

In a great number of publications, newly synthetized materials for the manufacturing of implantable devices were described, which involved the need for sterilization $[7,8,56,63]$. The method for sterilizing the product can affect the biocompatibility and performance of the DDSs, for instance by altering the thermomechanical properties of SMPs. Steam sterilization would be risky due to the high temperatures required $\left(121-132{ }^{\circ} \mathrm{C}\right)$, which can potentially melt or change the intrinsic structure of the material. Although ethylene oxide and low temperature plasma sterilization are carried out at lower operating temperatures, the former involves proper aeration of the device, as the gas is inherently toxic, and the latter may affect the surface chemistry and toxicity of the DDS due to vapor residuals and hydroxyl radicals associated with the plasma phase. On the other hand, $\gamma$-rays and ebeam irradiation can be associated with changes in the molecular weight of the SMP and both crosslinking and scission of its chains. Therefore, irradiation could affect not only biocompatibility of a selected polymer but also the degradation rate in the case of materials designed to be biodegradable. Notably, any sterilization method operates at temperatures above body temperature. Considering that many of the systems described were fine-tuned to show shape recovery at body 
temperature, sterilization may result in premature deployment if the device is sterilized in its temporary shape. To overcome such an issue, some researchers have proposed to make use of the water uptake process that occurs in vivo, having the water working as a plasticizer and decreasing the SMP activation temperature. This would foster stability of the device at higher temperature during sterilization without affecting its shape memory capability in biological fluids (i.e. at body temperature in contact with water). On the other hand, in vivo water uptake may proceed slowly and this could be an issue with regards to the kinetics of the activation process. In addition, the mechanical properties of the device may be negatively modified over time with the water uptake. Indeed, the presence of water would increase the polymer free volume and promote chain flexibility at a given temperature. Also, hydrogen bonds between water molecules and possible hydrogen-bond acceptors in the polymer chain may weaken the polymer-polymer interaction and further contribute to the increased chain flexibility. Due to all the above-mentioned criticalities, despite the increase in the costs of manufacturing, asepsis production methods could turn out mandatory. However, challenges still remain about how to prevent early activation of the shape memory device during storage and shipping. Use of packaging constraints, as done for alloys, may prevent the device from deploying in the case of undesired temperature increase. However, the same constraints may determine further challenges for sterilization. In addition, if the device is built to be activated at body temperature, there would be a narrow gap between storage temperature, typically room temperature, and activation temperature, which may cause its premature activation. For this reason, researchers have also considered other triggers, such as electromagnetic field and ultrasound, to enable an increase in temperature for the DDS only once administered. This strategy would allow to set a higher activation temperature for the device as the source of indirect heating would be limited to affect the device. This approach would need extra equipment and has anyway the potential to overheat the surrounding tissues with relevant damages. At the same time, in vitro and in vivo studies should be performed to understand compatibility and toxicity of the resulting item, taking in mind that these characteristics are dependent on the tissue in which the system is intended to perform [39,7,8,64,71]. The time during 
which the system is to be maintained in a specific tissue plays a pivotal role, and thus material biodegradability should be considered. Biodegradation is mainly caused by hydrolytic bond cleavage, the rate of which is in turn affected by diffusion processes. In the case of slow diffusion into the polymer matrix, this could lead to a degradation gradient from the surface to the core of the device, with a high degradation rate at the surface. As a result, the system appears reduced in size, but it may maintain its integrity and behavior at the core level. By contrast, when diffusion is faster than hydrolysis, degradation takes place all over the polymer matrix, thus resulting in bulk degradation. During this time, mechanical properties of the device should be so as to avoid damage to the tissue or acute inflammation would occur.

\subsubsection{D printing}

Considering SMPs processing into the original shape, the advent of 3D printing technologies has further widened the range of applications of these materials by providing the tool for 4D printing [79 [80-85]. This term was used for the first time in 2013 by Tibbits during a TED talk to highlight time as a new dimension for the development of 3D objects. In this respect, 4D printing was described to entail either materials that can change from one programmed shape to another or multi-material prints with the capability to transform over time, thus overcoming the concept of $3 \mathrm{D}$ printed objects as static structures. Afterwards, being employed by different other researchers, the meaning of this term was expanded to indicate any targeted evolution of 3D printed structures, in terms of shape, properties and functionality. Over time, 4D printing has taken on a main meaning by referring to the fabrication, via different 3D printing techniques and using smart materials as feedstocks, of items showing selftransformation ability, after production and in response to an external stimulus [26,86-90]. Although the main changes occur in size and shape of the object, these make also possible to modify the relevant performance and to achieve new functionalities.

Morphological changes in the end-product when exposed to a certain stimulus might depend on the use of smart materials as such and in combination, on the manipulation of the design and on the 
printing orientation as well as composition of layers. In this respect, in addition to the $\mathrm{x}, \mathrm{y}$ and $\mathrm{z}$ axis for the definition of a shape, 4D printing takes into account also how these coordinates change over time during the transformation. The basic principle of 4D printing is to create precisely controlled localized internal stress within a printed structure, which upon subsequent release of this stress can undergo further 3D shape shifting in a predictable manner [81,86,90-93]. In this respect, deformation mismatch and shape memory effect are the main ways to attain $4 \mathrm{D}$ printing. A deformation mismatch is typical of multi-material objects and may be induced by the relevant differences in physical properties, such as thermal expansion coefficient and swelling ratio. By way of example, 4D printed structures investigated so far were purposely designed to entail rigid polymeric structures and hydrogels. The diffusion of water into the hydrogel polymeric network would cause a specific and localized swelling, thus ensuring an evolution of the overall item shape in a controlled way. Alternatively, 4D printing could rely on the use of SMPs even for single composition items. These are the applications we found relevant in this review. In those cases, 4D printing also involved a socalled smart design phase, which has to take account of the original shape, the temporary shape, the transformations undergone by the object to shift from one another and relevant mechanisms.

3D printing technology has found main application in the pharmaceutical field for the development of personalized medicines, thanks to the versatility in composition, geometry and performance of drug products it can bring about [47,51,55,94-97]. In this respect, 4D printing holds even greater potential in tailoring to the needs of a specific patient, being able to define at the same time not only the characteristics the DDSs would have during administration but also those acquired at the target site prior, during or after the release of the drug. This would be particularly interesting in the case of implants that should be placed in a specific body area and whose shape should be adapted to the characteristics of the subject to be treated. As 4D printing involves the use of technologies still relatively little known in the pharmaceutical field, where formulation and process parameters are heavily conditioned by the need to comply with stringent quality and safety requirements, the number of applications proposed so far in the scientific literature are very limited and there is still no full 
awareness of what they might be. However, they are expected to largely grow in the next years, bringing a deeper understanding of $4 \mathrm{D}$ printing technique from the material, manufacturing and transformation over time points of view.

\section{DDSs based on SMMs}

Gene therapy and precision dosing, as well as the research for more effective and efficient production models, especially in view of the reduction in manufacturing scale associated with personalized medicine, seem to represent the new frontiers for the pharmaceutical field [48,98-107]. These applications would take advantage of new fabrication methods and drug delivery strategies, which SMMs could enable. Indeed, the use of such materials might represent a promising strategy to broaden the boundaries of traditional drug delivery and for the development of the so-called smart DDSs. As a part of a very innovative research topic, putting therapeutic needs before patient compliance has been already demonstrated to impact on adherence to the treatment, with important economic and epidemiological consequences, and this should not be disregarded [108-110]. In this respect the development of DDSs relying on SMMs may provide significant improvements: $i$ ) new ways to trigger drug release besides time-, rate- and site-dependent approaches and ii) increased freedom to design systems able to settle, adapt or remain and then release the conveyed drug, in the target districts or move away from them. These goals could even be attained overcoming the limitations associated with the conditions of administration, such as frequency, invasiveness and need for hospitalization. Before the advent of smart DDSs, SMMs were already widely studied for biomedical applications, in particular for the production of drug-free stents and scaffolds. As a natural evolution, since the mid2000s, a research line was launched aimed to explore the feasibility of new materials to be used for the development of implantable DDSs. These polymers were intended to combine shape-memory effect at body temperature, to enable administration via minimally invasive implantation, biodegradability, to avoid a second surgery for removal, and controlled release of drugs, to pursue a range of therapeutic benefits [77-79,111-113]. With the idea of broadening the range of available 
multifunctional materials - i.e. polymers showing different independent functionalities - and to tailor In this respect, a fine tuning of various molecular parameters was carried out during the synthetic process. By way of examples, polyurethane-poly lactide-co-glycolide and polyurethane-poly-Llactide/polyethylene glycol, polyestermethacrylate copolymers, copolyester urethanes, AB-polymer networks having cooligoester and poly(n-butyl acrylate) segments, polydiolcitrate polyester elastomers, poly(L-lactide-co-glycolide-co-trimethylene carbonate $)$ and $\operatorname{poly}(\varepsilon-$ caprolactone)/trisilanolphenylpolyhedraloligomericsilsequioxan networks were proposed. Overall, temperature-sensitive multilaterals were mainly proposed with a few examples of shape memory polymers based on supramolecular interaction. The research works were thus focused on the design and the application of a characterization strategy involving the evaluation of $i$ ) polymer network architectures (e.g. crosslinking density, molecular weight), ii) polymer biocompatibility, biodegradability, thermo-mechanical and shape memory properties, even in an aqueous environment as water may act as a plasticizer, iii) feasibility of drug incorporation in the polymeric network, either before the relevant synthesis or in the resulting material by soaking, iii) influence of drug properties (e.g. solubility, hydrophilic-lipophilic balance, molecular weight), loaded amount and incorporation method on the thermo-mechanical and shape memory properties of the material, and release performance as well as biodegradability of the system. On the other hand, what has not yet been addressed in these research works was the design concept of the DDSs, i.e. the shape and dimension in which they were manufactured and that would be recovered in vivo, the site of administration and the target area for the release of drugs, the molecule conveyed and the therapeutic use. Only welldefined DDSs relying on the use of SMAs and SMPs have been considered in detail and are presented in the following 2.1-2.4 Sections, being classified according to the objective for which the recovery of the original shape was exploited. Particularly, the temporary administered shape, the original recovered one and the stimulus employed for activation of the shape memory effect were highlighted. The most common triggering mechanism used was that of body temperature and was indicated as 
direct heating. SMPs proposed for the development of DDSs were most frequently represented by purposely synthetized and in-house crosslinked polymers to obtain the network enabling the desired shape recovery effect, in terms of triggering conditions (e.g. temperature, supramolecular composition), efficiency of recovery (e.g. shape fixity and shape recovery ratio) and mechanical characteristics of the device. This could pose a major limitation since biocompatibility, quality and safety of the DDSs need to be demonstrated. Only in few cases, commercially available starting materials were employed as such.

Overall, systems at an early development stage were presented. In this respect, the research works reviewed mainly involved use of tracers or model drug molecules, simple study of model original and temporary shapes, rare adoption of industrially scalable manufacturing techniques, with preference to manual fabrication processes, in vitro studies of the shape memory behavior and release performance, few ex and in vivo data obtained in animal models or cadavers. Therefore, an effort was made to describe and summarize in the following Tables the research level achieved for the systems described in the reviewed articles, the innovation features and the possible room for improvement identified by the authors themselves.

\subsection{Shape recovery for reaching the target area}

In one main application, the shape recovery of nitinol provided a DDS with the ability to deliver drugs into the eustachian tube after being administered through the nasal cavity [121]. This approach would in principle allow to treat sudden hearing loss with no need for invasive insertion in the middle ear and overcoming the limits of movement in the nasopharyngeal cavity imposed by the nasal vestibule. The main features of this system are summarized in Table 1.

Tendon-driven manipulators with a size in the range of $\mathrm{mm}$ are generally used for transnasal administration. The availability of an actuator based on the nitinol shape memory effect can be considered particularly interesting as this material is characterized by excellent strength to weight ratio, thus enabling device miniaturization without losing performance. This way, a good distal 
control of the device is maintained even in very tortuous administration paths, thus making the drug

administration safer. Conversely to other active DDSs, no expensive microelectromechanical systems

(MEMS) technology would be required for providing heating to trigger the shape recovery. In fact, the actuation would be obtained by Joule heating of the alloy, connected to an external direct current power supply through copper wires to overcome battery life limitations.

Table 1: DDSs for which the shape recovery effect allowed to reach the target area

\begin{tabular}{|c|c|}
\hline Reference & {$[121]$} \\
\hline SMM & Commercial nitinol \\
\hline Brief description of the system & $\begin{array}{l}\text { Nitinol wire enclosed in a stainless steel ribbon spring, working } \\
\text { antagonistically to the wire. A flexible tube acting as a drug reservoir inserted } \\
\text { into the wire-ribbon assembly and connected to an external syringe for } \\
\text { pumping the drug. }\end{array}$ \\
\hline Administration route & Insertion in the middle ear through the nasopharyngeal cavity \\
\hline Temporary (administered) shape & Curved shape \\
\hline Triggering stimulus & Indirect Joule heating via an external direct current power supply \\
\hline Original (recovered) shape & Straight shape \\
\hline Target area for drug release & Eustachian tube (middle ear) \\
\hline Therapeutic goal & Treatment of sudden hearing loss \\
\hline Loaded drug/tracer & A dye solution \\
\hline $\begin{array}{l}\text { Main advantages / Innovation } \\
\text { features }\end{array}$ & $\begin{array}{l}\text { Capability of the system to navigate through tortuous paths characterized by } \\
\text { wide range of dimensions } \\
\text { High distal control } \\
\text { Passive activation leading to cost reduction }\end{array}$ \\
\hline Research level & $\begin{array}{l}\text { Design concept and preliminary in vitro studies (arranging a set of loosely } \\
\text { placed rings based on the anatomy of the middle ear) and ex vivo studies (on } \\
\text { a cadaver head) with a tracer }\end{array}$ \\
\hline $\begin{array}{l}\text { Room for improvement identified by } \\
\text { the authors }\end{array}$ & Relatively high activation temperature \\
\hline
\end{tabular}




\subsection{Shape recovery for enabling retention in the target area}

The ability of SMMs to take on a shape, different from that in which they were administered, bulkier or otherwise suitable for being retained in a specific body region, was applied for the design of implants/scaffolds, stents and systems specifically devised either for being maintained within hollow organs (e.g. stomach, bladder or vagina) or for wound treatment. By extending the residence time of DDSs, inherently designed to control rate or time of release, complex release performance and new therapeutic targets became accessible.

These DDSs were conceived with a temporary shape such as to ease the conditions of administration when these involved sites inside the human body that are rather difficult to reach, without impacting the ability of the systems to remain in the target areas and release their content. In fact, the latter objectives were fulfilled by the recovered original shape. On the other hand, the temporary shape could, for example, allow to insert the DDS into a catheter, make it injectable through syringes, swallowable and even implantable by minimally invasive surgery.

In the following Tables 2-5 the main features of the systems proposed so far in the literature, which were subdivided on the basis of the route, mode or objective of administration, were summarized. In particular, the SMMs employed and main characteristics of the DDSs were briefly described including the site of administration/release, the therapeutic goal pursued, the administered temporary shape as well as the recovered original one, and the triggering stimulus.

\section{$\underline{2.2 .1 \text { Implants/Scaffolds }}$}

SMMs have found an interesting use in the pharmaceutical field in response to the strong clinical trend towards minimally invasive surgery (Table 2). Indeed, implantation of initially small objects, that only in situ may gain a bulkier configuration with the desired shape and functionality, would be highly advantageous $[113,122]$. Only a few systems were proposed for specific administration sites, such as bones and cartilage, while the great majority of the applications reviewed were mainly 
focused on general tissue and vascular regeneration, on the release of anti-bacterial and anti-

In the field of tissue engineering, SMMs have also enabled evolution of scaffolds, i.e. from devices having poorly versatile and editable physical/chemical properties, to implants designed for the growth of cells and the release of drugs intended, for instance, to promote repair or regeneration of tissues. In consideration of the high cost and limited bio-security of scaffolds containing in vitro-grown cells, cell-free shape-memory scaffolds were then proposed [122]. Porosity, which affects the formation of blood vessels through the scaffold, and biodegradation, required to occur in a specific period of time in order to make space for the grown tissue to take over, are of crucial importance in the development of scaffolds [125-127]. In this respect, hydrogels showing shape memory effect were widely employed in cell culture and tissue engineering as their internal structure easily allowed to provide enough support for cell growth using a limited amount of material. However, there was no effective ways to control the internal structure of the resulting systems. To overcome such a challenge, 4D printing relying on gel extrusion 3D printing was successfully tested for the fabrication of scaffolds based on shape memory hydrogels characterized by a good control of the internal mesh structure [128]. Notably, in such a system the shape memory effect was triggered by supramolecular interactions (i.e. removal of calcium ions). This strategy was used to avoid temperature triggering, but still lacks the identification of a suitable procedure to activate the shape recovery in vivo. In most of the manuscripts considered, temperature-responsive SMMs were investigated to fulfill the need for administering implants through minimally invasive surgery [122,123]. Besides being biodegradable and characterized by suitable mechanical properties they should also enable the control of drug release in terms of time, rate and site. Not only typical polymeric prolonged-release matrices were proposed, but also multiple-unit systems based on bonded microspheres $[42,123]$. Such systems were produced, programmed and administered as a single whole unit, but showed the ability to maintain the independent release performance of the subunits. 
With respect to the stimulus triggering the shape recovery behavior, direct heating was often used in vitro but the relevant application in vivo remains an open question, especially in view of the relatively high temperatures required. Thus, indirect heating sources were investigated. By way of example, high intensity focused ultrasound (HIFU) was tested as an interesting triggering stimulus because the beam can be collimated into a tight focal spot of about $3 \mathrm{~mm}$ and can show a prominent selective heating effect $[42,44]$. SMPs can absorb the mechanical energy generated by viscous shearing oscillation exerted by focused ultrasound and subsequently relax, releasing the energy in the form of heat. Besides being well-known for the ability to penetrate much deeper into the body with respect for instance to light, HIFU could also be involved in controlling drug release. In the systems investigated, ultrasound waves were demonstrated able to trigger drug release via thermal and cavitation effects. Indeed, the temperature rise would determine swelling of the polymeric network and increase in the relevant permeability. On the other hand, ultrasound waves passing through a liquid determine the creation of microbubbles that grow and collapse in a few microseconds, thus generating high speed microstream and shock waves on the surface of the polymer matrix. These would promote the pentration of water into the polymeric network leading to drug dissolution and diffusion outside. In addition, HIFU was proved able to selectively heat the devices, even at high temperatures, without warming in a risky mode the surrounding environment and causing possible tissue damage. Such a localized heating could also be exploited to trigger shape recovery only in predefined areas of the DDS. However, the use of an indirect heating source would require an extra equipment to have the system perform correctly, thus increasing the cost of therapy.

Many of the proposed systems were in a preliminary stage of development, entailing prototypes having model shapes (e.g. I, U or cylindrical shapes), and were not provided with a geometry specially designed for the final application. Since they consisted of polymers/copolymers either purposely synthesized or crosslinked to give rise to the shape memory effect, biocompatibility and biodegradability, the latter being particularly challenging for implant removal at the end of their 
performance, have started to be approached but would benefit from further investigation, especially 1 after identifying a specific therapeutic goal/target area for each system. 
Table 2: DDSs for which the shape recovery effect allowed prolonged retention in the target area: implants/scaffolds

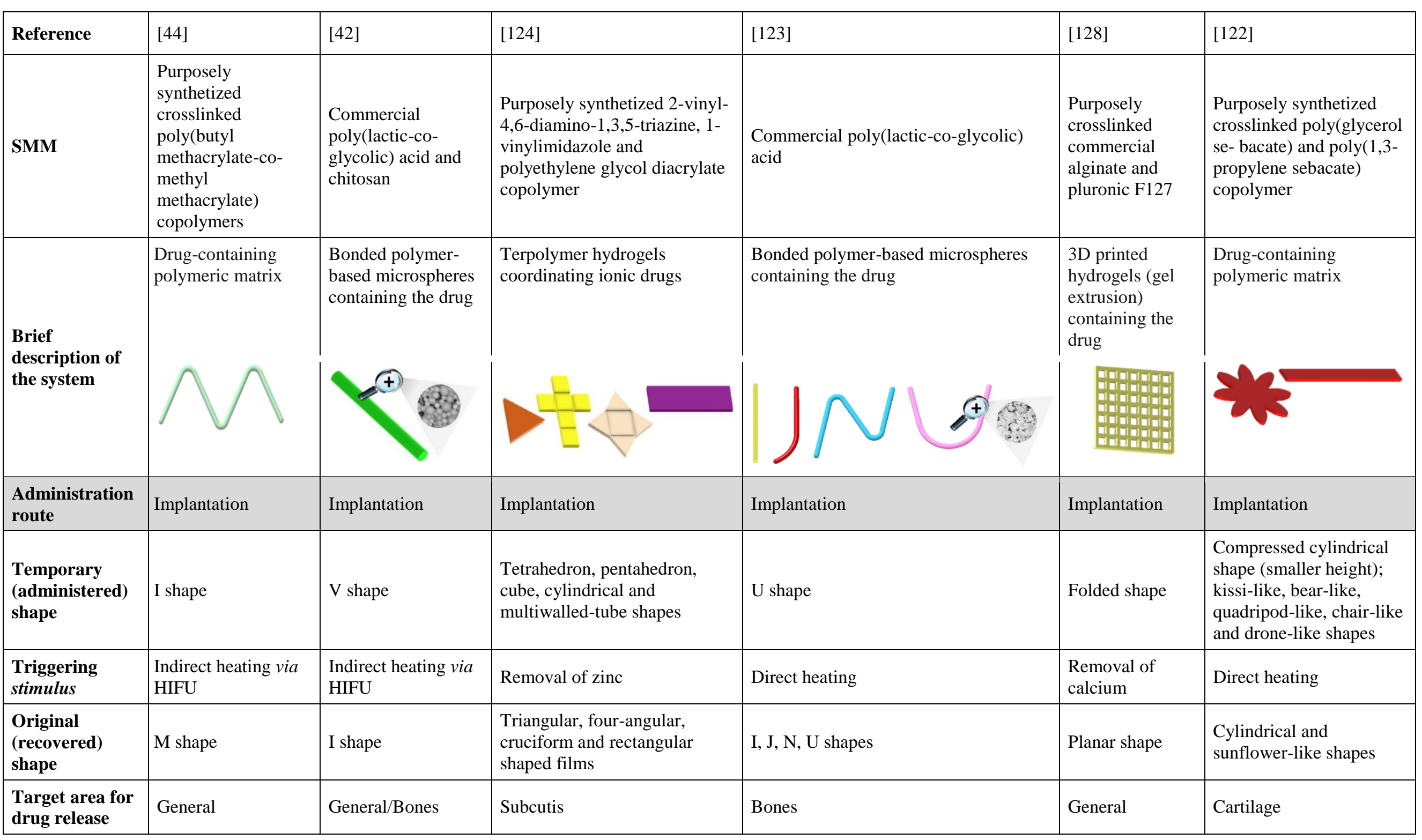




\begin{tabular}{|c|c|c|c|c|c|c|}
\hline $\begin{array}{l}\text { Therapeutic } \\
\text { goal }\end{array}$ & $\begin{array}{l}\text { Tissue and vascular } \\
\text { regeneration }\end{array}$ & Tissue regeneration & $\begin{array}{l}\text { Anti-bacterial and anti- } \\
\text { inflammatory activity to } \\
\text { prevent implant failure and } \\
\text { promote wound healing }\end{array}$ & $\begin{array}{l}\text { Tissue regeneration and prevention of } \\
\text { relevant infections }\end{array}$ & $\begin{array}{l}\text { Tissue } \\
\text { regeneration }\end{array}$ & Tissue regeneration \\
\hline $\begin{array}{l}\text { Loaded } \\
\text { drug/tracer }\end{array}$ & Copper sulfate & $\begin{array}{l}\text { Fluorescein } \\
\text { isothiocyanate- } \\
\text { labeled lysozime }\end{array}$ & Zinc & $\begin{array}{l}\text { Vancomycin and vancomycon- } \\
\text { rhodamine B }\end{array}$ & Methotrexate & Kartogenin \\
\hline $\begin{array}{l}\text { Main } \\
\text { advantages / } \\
\text { Innovation } \\
\text { features }\end{array}$ & $\begin{array}{l}\text { Use of localized } \\
\text { heating to promote } \\
\text { shape recovery of } \\
\text { selected parts (switch } \\
\text { on-off behavior with } \\
\text { fine-control) } \\
\text { Shape recovery also } \\
\text { triggers drug release }\end{array}$ & $\begin{array}{l}\text { Shape recovery also } \\
\text { triggers drug release } \\
\text { Modulation of shape } \\
\text { recovery extent and } \\
\text { drug release } \\
\text { (pulsatile release) } \\
\text { obtained by varying } \\
\text { the HIFU output } \\
\text { power } \\
\text { Biodegradability }\end{array}$ & $\begin{array}{l}\text { Fine-tuning of the mechanical, } \\
\text { shape memory and release } \\
\text { controlling capabilities } \\
\text { Biocompatibility }\end{array}$ & $\begin{array}{l}\text { Release performance of the system } \\
\text { different from that of single microsphere } \\
\text { components } \\
\text { Biodegradability }\end{array}$ & $\begin{array}{l}\text { Suitable for short } \\
\text { term } \\
\text { implantation } \\
\text { 4D printing } \\
\text { Biocompatibility } \\
\text { Biodegradability }\end{array}$ & $\begin{array}{l}\text { High porosity } \\
\text { Shape memory effect also } \\
\text { considering complex } \\
\text { configurations } \\
\text { Biocompatibility } \\
\text { Biodegradability }\end{array}$ \\
\hline Research level & $\begin{array}{l}\text { Design concept and } \\
\text { preliminary in vitro } \\
\text { studies }\end{array}$ & $\begin{array}{l}\text { Design concept and } \\
\text { preliminary in vitro } \\
\text { studies with a tracer }\end{array}$ & $\begin{array}{l}\text { Design concept and preliminary } \\
\text { in vitro and in vivo (rats) studies }\end{array}$ & $\begin{array}{l}\text { Design concept and preliminary in vitro } \\
\text { studies }\end{array}$ & $\begin{array}{l}\text { Design concept } \\
\text { and preliminary } \\
\text { in vitro studies }\end{array}$ & $\begin{array}{l}\text { Design concept and } \\
\text { preliminary in vitro and in } \\
\text { vivo (rats) studies }\end{array}$ \\
\hline $\begin{array}{l}\text { Room for } \\
\text { improvement } \\
\text { identified by the } \\
\text { authors }\end{array}$ & - & - & $\begin{array}{l}\text { Poorly investigated } \\
\text { coordination capabilities }\end{array}$ & $\begin{array}{l}\text { Relatively long degradation time } \\
\text { Relatively high activation temperature }\end{array}$ & $\begin{array}{l}\text { Relatively long } \\
\text { time needed for } \\
\text { complete } \\
\text { recovery }\end{array}$ & - \\
\hline
\end{tabular}




\subsubsection{Stents}

Stents are tubular structures widely used in surgery to prevent the closure of vessels or ducts (e.g. esophagus, urethra, bronchi) $[32,33,129,130]$. According to the insertion procedure and expected duration, various metal stents have been proposed over time, intended to fulfill a series of physical, mechanical and chemical requirements. Already in 2006 approximately half of the stents produced worldwide were made of SMAs, and of nitinol in particular, taking advantage of the relevant superelastic behavior [29,31,131]. Particularly, vascular self-expanding stents represent the most successful biomedical application of SMAs, both in terms of therapeutic goals achieved and impact on the market. The main limitation showed by these products was restenosis observed about 6 months after implantation, hence the need for percutaneous interventions for their removal [132]. Moreover, cell proliferation and thrombus formation often occurred, leading to stent failure. To counteract such issues, strategies based on coating the stent surface with noble materials (e.g. gold), biocompatible polymers as well as heparin were pursued $[133,134]$. The research has then moved towards SMPs as these enabled the production of biodegradable (not inducing restenosis) and biocompatible (reducing the risks of thrombus formation) stents, which were also implantable through minimally invasive surgery [135-137]. In fact, stents could be manufactured with the desired final diameter and then programmed with a smaller diameter so as to facilitate the correct positioning in situ, prevent early elastic recoil as well as negative vessel remodeling, and avoid any auxiliary devices for triggering the shape modification (e.g. balloons). Moreover, the use of thermoplastic SMPs could enable the manufacturing of stents via cost-effective hot-processing techniques and possibly by 3D printing, making them suitable for customization.

More recently, shape memory polymeric stents were also implemented for the controlled release of drugs (i.e. drug-eluting stents) (Table 3). These turned out to be mainly intended for vascular application, not only ensuring local delivery of drugs to reduce inflammation, restenosis rate and risk of thrombus formation (e.g. antiproliferative and antiplatelet drugs), but also for delivering immunosuppressants to prevent rejection [135-137]. Chemo-responsive and temperature-triggered 
SMPs were generally employed for the manufacturing of helix-shaped prototypes because this design would offer better mechanical resistance [136]. Indeed, in addition to biocompatibility, biodegradation, release performance, which were features studied for many other applications, platelet adhesion and mechanical properties of the stents as well as their ability to maintain the vessels open during their whole life were considered fundamental. In preliminary studies, these properties were evaluated at least by using high pressure vessel models. However, type and duration of stressful conditions as well as the impact of the biodegradation process on the mechanical resistance of stents should also be considered, taking the characteristics of the blood district actually involved into special account $[133,136,137,138]$. 
Table 3: DDSs for which the shape recovery effect allowed prolonged retention in the target area: stents

\begin{tabular}{|c|c|c|c|c|c|c|}
\hline Reference & [132] & {$[133,134]$} & [138] & {$[136]$} & {$[135]$} & [137] \\
\hline SMM & $\begin{array}{l}\text { Commercial } \\
\text { polyurethane }\end{array}$ & $\begin{array}{l}\text { Purposely crosslinked } \\
\text { commercial chitosan }\end{array}$ & $\begin{array}{l}\text { Purposely synthetized } \\
\text { poly(ester-urethanes) }\end{array}$ & $\begin{array}{l}\text { Purposely synthetized } \\
\text { crosslinked } \\
\text { polyethylene glycol and } \\
\text { poly( } \varepsilon \text {-caprolactone) } \\
\text { block copolymers }\end{array}$ & $\begin{array}{l}\text { Commercial poly-lactic } \\
\text { acid and poly (lactic-co- } \\
\text { glycolide) }\end{array}$ & $\begin{array}{l}\text { Commercial poly ( } \varepsilon- \\
\text { caprolactone) and } \\
\text { poly(propylene } \\
\text { carbonate) }\end{array}$ \\
\hline $\begin{array}{l}\text { Brief description of } \\
\text { the system }\end{array}$ & $\begin{array}{l}\text { Polymer matrix } \\
\text { containing the drug }\end{array}$ & $\begin{array}{l}\text { Uncoated and heparin- } \\
\text { coated polymer matrix } \\
\text { containing the drug }\end{array}$ & $\begin{array}{l}\text { Polymer matrix } \\
\text { containing the drug }\end{array}$ & $\begin{array}{l}\text { Coated polymer matrix } \\
\text { containing drugs in the } \\
\text { core structure and in the } \\
\text { coating film }\end{array}$ & $\begin{array}{l}\text { Polymer matrix } \\
\text { containing the drug }\end{array}$ & $\begin{array}{l}\text { Polymer matrix } \\
\text { containing the drug }\end{array}$ \\
\hline Administration route & Implantation & Implantation & Implantation & Implantation & Implantation & Implantation \\
\hline $\begin{array}{l}\text { Temporary } \\
\text { (administered) shape }\end{array}$ & Elongated-tube shape & Crimped-helix shape & $\begin{array}{l}\text { Helix shape of smaller } \\
\text { diameter }\end{array}$ & Straight shape & $\begin{array}{l}\text { Helix shape of smaller } \\
\text { diameter }\end{array}$ & Straight shape \\
\hline Triggering stimulus & Direct heating & Hydration & Direct heating & Direct heating & Direct heating & Direct heating \\
\hline $\begin{array}{l}\text { Original (recovered) } \\
\text { shape }\end{array}$ & Tube shape & Helix shape & Helix shape & Helix shape & Helix shape & Helix shape \\
\hline $\begin{array}{l}\text { Target area for drug } \\
\text { release }\end{array}$ & $\begin{array}{l}\text { Blood vessels in the } \\
\text { cardiac area }\end{array}$ & Blood vessels & Blood vessels & Blood vessels & Blood vessels & Blood vessels \\
\hline Therapeutic goal & $\begin{array}{l}\text { Reduce the risk of } \\
\text { restenosis, thrombus } \\
\text { formation, } \\
\text { inflammation and } \\
\text { vascular disfunction }\end{array}$ & $\begin{array}{l}\text { Decrease neointimal } \\
\text { hyperplasia }\end{array}$ & $\begin{array}{l}\text { Decrease neointimal } \\
\text { hyperplasia }\end{array}$ & $\begin{array}{l}\text { Reduce platelet } \\
\text { adhesion and } \\
\text { hyperproliferation } \\
\text { (antiproliferative and } \\
\text { anticoagulant action) }\end{array}$ & $\begin{array}{l}\text { Reduce platelet } \\
\text { adhesion }\end{array}$ & $\begin{array}{l}\text { Reduce the risk of } \\
\text { restenosis, thrombus } \\
\text { formation, inflammation } \\
\text { and vascular disfunction }\end{array}$ \\
\hline Loaded drug/tracer & Not disclosed drugs & Sirolimus, Heparin & Paclitaxel & Mitomycin C, Curcumin & Tacrolimus & Metoprolol tartrate \\
\hline
\end{tabular}




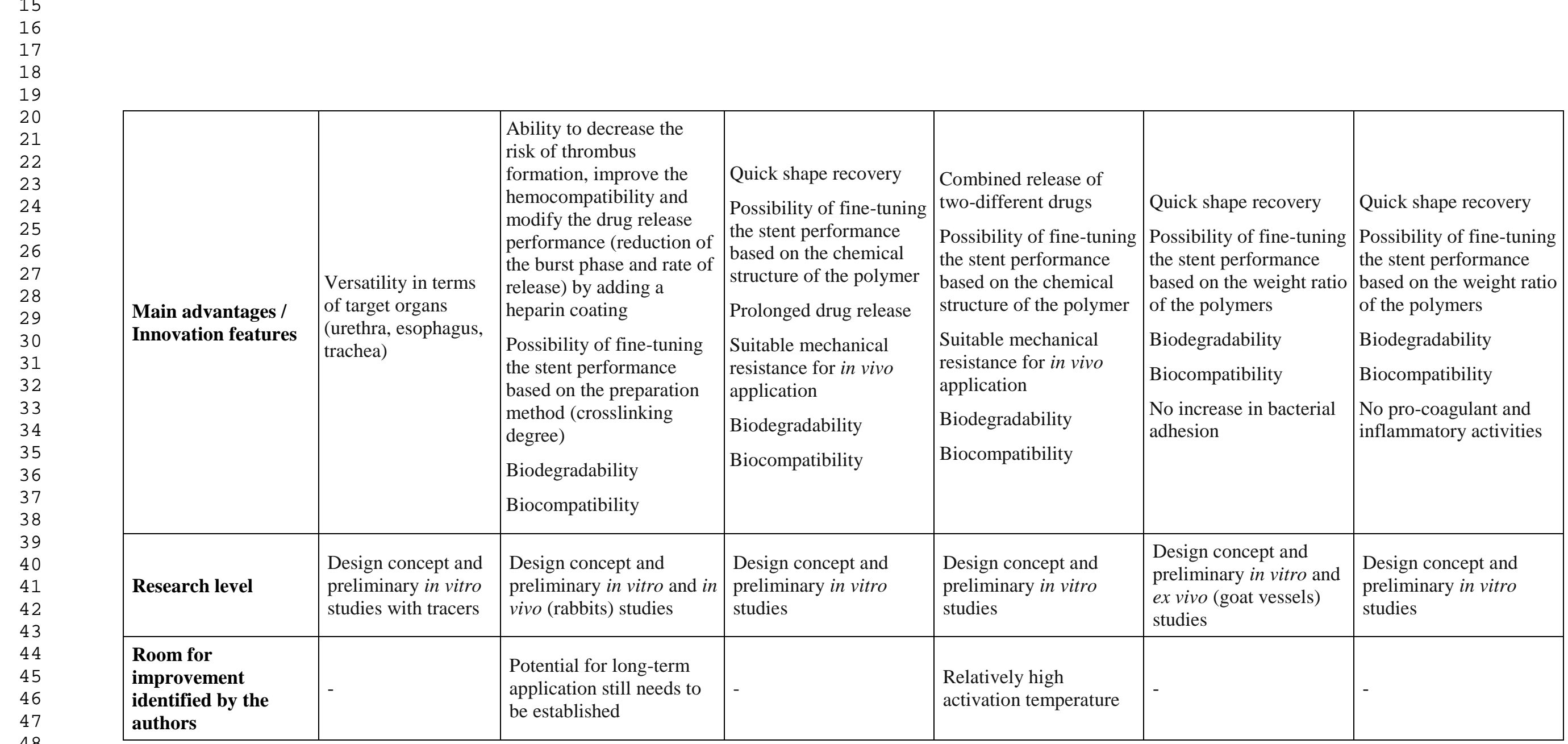




\section{$\underline{2.2 .3 \text { Intra-organ systems }}$}

Prolonged-release of drugs in a target site is mainly pursued for the purpose of reducing the frequency of administration, the drug strength and the side effects of a therapy, improving efficacy and patient compliance [139]. In hollow muscular organs such as the stomach and urinary bladder, such a release mode, should be accompanied by the easy insertion of the DDSs into the target area and the relevant retention as long as necessary. This, in the case of chronic treatments, could even last for months. Non-invasive removal/elimination from the organ at the end of the performance would also be an advantageous additional feature. Taking these premises into account, SMPs were used to develop DDSs with original shapes and mechanical properties suitable for the retention into the selected hollow organs, to be fixed into temporary shapes enabling comfortable and minimally invasive administration (Table 4). The latter turned out to be of suitable spatial encumbrance for being inserted into a urethral or vaginal catheter, or conveyed inside a commercial hard capsule for oral administration. Since these were DDSs designed for indwelling within specific sites, not only their mechanical characteristics and release performance, but also their design has been considered within the analysis already carried out in the preliminary studies. With respect to the SMPs employed, poly(vinyl alcohol) offering the advantage of a long-established use in the formulation of drug products and safety profile, exhibited water-induced shape memory response and good hotprocessability [140-143]. Different devices suitable for retention in the stomach and in the bladder were fabricated by hot melt extrusion and fused deposition modeling 3D printing. In the latter case, this resulted in one of the first application of $4 \mathrm{D}$ printing for the development of DDSs using commercially available pharmaceutical-grade polymers with no need for any chemical modification and employing the fused deposition modeling technique. The matrix systems proposed showed prolonged release, further fine-tuned by applying external coatings with different permeability, and dissolution/erosion behavior enabling safe elimination from the target organs with no need for invasive removal procedures. Also a commercial shape memory polyurethane was employed for the 
manufacturing of an intravaginal device including a flux controlled pump, in which the release control 1 2 function was decoupled from the shape memory effect [144]. 
Table 4: DDSs for which the shape recovery effect allowed prolonged retention in the target area: gastroretentive, intravaginal and intravesical systems

\begin{tabular}{|c|c|c|c|}
\hline Reference & [144] & [142] & {$[143]$} \\
\hline SMM & Commercial polyether urethane & Commercial poly(vinyl alcohol) & Commercial poly(vinyl alcohol) \\
\hline \multirow{2}{*}{\multicolumn{4}{|c|}{$\begin{array}{l}\text { Flux controlled pump, composed of a rigid polymer } \\
\text { envelop having orifices for fluid influx and efflux, } \\
\text { filled with a drug containing tablet and coupled with a } \\
\text { shape memory retainer }\end{array}$}} \\
\hline & & & \\
\hline Administration route & Intravaginal (by catheterization) & Intravesical (by catheterization) & $\begin{array}{l}\text { Oral (by swallowing into commercial } \\
\text { hard capsules) }\end{array}$ \\
\hline Temporary (administered) shape & Compressed ellipsoidal shape & I shape & Supercoiled and paper clip shapes \\
\hline Triggering stimulus & Direct heating & Direct heating and contact with water & Direct heating and contact with water \\
\hline Original (recovered) shape & Ellipsoidal shape & U and helix shapes & $\begin{array}{l}\text { Cylindrical and conical helices, S- and } \\
\text { atom-like shapes }\end{array}$ \\
\hline Target area for drug release & Vagina & Bladder & Stomach \\
\hline Therapeutic goal & $\begin{array}{l}\text { Prolonged release of macromolecules for the treatment } \\
\text { of sexually transmitted infections, endometriosis and } \\
\text { uterine fibroids }\end{array}$ & $\begin{array}{l}\text { Prolonged release of drugs in the bladder } \\
\text { for treatment of local diseases overcomimg } \\
\text { failures and discomfort connected with } \\
\text { repeated instillations through catheters }\end{array}$ & $\begin{array}{l}\text { Prolonged release of drugs having an } \\
\text { absorption window in the upper } \\
\text { gastrointestinal tract, lower } \\
\text { solubility in the intestinal environment } \\
\text { or employed to treat local patologies }\end{array}$ \\
\hline Loaded drug/tracer & $\begin{array}{l}10 \mathrm{kDa} \text { rhodamine B dextran, 5-(and-6)- } \\
\text { carboxytetramethyl rhodamine labelled insulin }\end{array}$ & Caffeine & Allopurinol \\
\hline
\end{tabular}




\subsubsection{Systems for wound treatment}

Injuries are typically treated by the application of wound dressing in ordered to foster relevant healing [145]. This is a challenging process involving both proliferation and migration of cells, leading to tissue regeneration. Therefore, systems devised for wound treatment have to fulfill a series of requirements, such as providing a suitable microenvironment for cell growth, for instance being semipermeable and highly porous to ensure sufficient gas and nutrient exchange. Moreover, they should be characterized by specific mechanical properties (e.g. good stretching ability and suitable mechanical strength), be sterile and able to prevent bacterial infection. In this respect, a relatively high water vapor transmission ratio, enabling appropriate wound drying, would be highly advantageous. A particular wound treatment is that obtained by the application of surgical sutures to reconnect tissues and restore their structure as well as function [146,147]. This application remains challenging especially in the case of minimally invasive surgeries, during which knotting a suture is hindered by the confined space and possible site infections.

In the field of application just described, SMMs were shown to provide the DDSs with smart performance, such as shape fixation-assisted easy application and shape recovery-assisted closure of wounds [145]. Wet and electrospinning processes turned out to be the most investigated techniques for the fabrication of prototypes conceived in the form of polymeric matrices and layered structures [146-148]. In the case of treatments requiring anastomosis, rings surgically applied following resection of bowel segments to enable accurate joining of two viable ends without any tension represent one of the most commonly employed systems [149]. In this respect, hydrogels having shape memory effect were proved effective in ensuring efficient reconnection. In addition, the original shape could even be rather slowly recovered, thus allowing gradual release of the applied pressure. Indeed, this behavior helped attain a better intestinal healing. Finally, the shape memory effect was also exploited to promote perfect seal of sutures even when applied loosely as a consequence of difficult procedures, especially in the case of limited room in the area affected by surgery [146]. 
The use of SMMs in the development of systems for wound treatment ultimately provided easy application and enhanced comfort, while speeding up the wound closure process. Overall, the devices reviewed were mainly characterized by anti-inflammatory/antibacterial activity, thanks to the presence of specific drugs, also of natural source. Notably, a few of these systems showed rapid clotting due to the presence of thrombogenic materials in the formulation and the high surface area of the entire device, associated with the peculiar microstructure [145]. In this respect, the use of nanofibers typically prepared through electrospinning technology was especially successful [145148]. Moreover, shape memory foams were devised for bleeding control, even in stressful conditions, such as in the battlefield and in high temperature environment [150]. Polyurethane currently represents a frequently used commercially available material for the development of embolic foams, but in this specific case it was purposely synthetized to also show the desired shape recovery behavior. Indeed, these DDSs were characterized by an expanded original shape and a compressed temporary one and showed an extremely quick shape memory effect once exposed to blood at body temperature. Besides surface area, porosity was found of utmost importance for the intended application and turned out not to be affected by the programming of the temporary shape and recovery of the original one. Considering the application of the devices belonging to this category to particularly sensitive areas and the use of direct heating as the main triggering stimulus, biocompatibility studies carried out on cell cultures of common fibroblasts still seem too preliminary, while more in depth in vivo evaluation should be envisaged. 
Table 5: DDSs for which the shape recovery effect allowed prolonged retention in the target area: systems for wound treatment

\begin{tabular}{|c|c|c|c|c|c|}
\hline References & {$[145]$} & [149] & {$[150]$} & {$[146,147]$} & [148] \\
\hline SMM & $\begin{array}{l}\text { Purposely-synthetized } \\
\text { polyurethane }\end{array}$ & $\begin{array}{l}\text { Purposely-crosslinked } \\
\text { poly(vinyl } \\
\text { alcohol)/gelatin } \\
\text { copolymer }\end{array}$ & $\begin{array}{l}\text { Purposely-synthetized } \\
\text { polyurethane }\end{array}$ & $\begin{array}{l}\text { Purposely-synthetized } \\
\text { polyurethane }\end{array}$ & $\begin{array}{l}\text { Purposely-synthetized } \\
\text { polyurethane }\end{array}$ \\
\hline \multirow{2}{*}{$\begin{array}{l}\text { Brief description } \\
\text { of the system }\end{array}$} & $\begin{array}{l}\text { Nanofibrous material composed } \\
\text { of gelatin, chitosan and shape } \\
\text { memory polyurethane, } \\
\text { containing the drug }\end{array}$ & $\begin{array}{l}\text { Hydrogel-based ring } \\
\text { containing the drug }\end{array}$ & $\begin{array}{l}\text { Polymeric foam containing } \\
\text { the drug }\end{array}$ & $\begin{array}{l}\text { Polymer-based nanofibers } \\
\text { containing the drug }\end{array}$ & $\begin{array}{l}\text { Three-layer polymer-based } \\
\text { nanofibers with two external } \\
\text { placebo layers and the internal one } \\
\text { containing the drug }\end{array}$ \\
\hline & & & & & \\
\hline $\begin{array}{l}\text { Administration } \\
\text { route }\end{array}$ & Topical application & Implantation & Injection & Implantation & Topical application \\
\hline $\begin{array}{l}\text { Temporary } \\
\text { (administered) } \\
\text { shape }\end{array}$ & Elongated rectangular shape & Compressed ring shape & $\begin{array}{l}\text { Cylindrical shape with } \\
\text { smaller diameter }\end{array}$ & Elongated cylindrical fibers & Elongated rectangular shape \\
\hline $\begin{array}{l}\text { Triggering } \\
\text { stimulus }\end{array}$ & Direct heating & Contact with water & $\begin{array}{l}\text { Direct heating and contact } \\
\text { with water }\end{array}$ & Direct heating & Direct heating \\
\hline $\begin{array}{l}\text { Original } \\
\text { (recovered) shape }\end{array}$ & Rectangular shape & Ring shape & Cylindrical shape & Cylindrical fibers & Rectangular shape \\
\hline $\begin{array}{l}\text { Target area for } \\
\text { drug release }\end{array}$ & Wounds & Bowel wounds & Wounds & Wounds & Wounds \\
\hline Therapeutic goal & $\begin{array}{l}\text { Promote healing of open } \\
\text { wounds reducing the risks of } \\
\text { bleeding, infections and } \\
\text { inflammation }\end{array}$ & $\begin{array}{l}\text { Create anastomosis } \\
\text { while reducing the } \\
\text { inflammation }\end{array}$ & $\begin{array}{l}\text { Stop bleeding and promote } \\
\text { blood clotting, while } \\
\text { reducing the risks of } \\
\text { infections }\end{array}$ & $\begin{array}{l}\text { Suture wounds while reducing } \\
\text { the risks of infections and } \\
\text { inflammation }\end{array}$ & $\begin{array}{l}\text { Promote healing of open wounds } \\
\text { reducing the risks of infections and } \\
\text { inflammation }\end{array}$ \\
\hline
\end{tabular}




\begin{tabular}{|c|c|c|c|c|c|}
\hline $\begin{array}{l}\text { Loaded } \\
\text { drug/tracer }\end{array}$ & Silver nitrate & Acetylsalicylic acid & Cinnamic acid & Berberine hydrochloride & Berberine hydrochloride \\
\hline $\begin{array}{l}\text { Main advantages / } \\
\text { Innovation } \\
\text { features }\end{array}$ & $\begin{array}{l}\text { High porosity } \\
\text { Stretching ability } \\
\text { Biocompatibility } \\
\text { Potential as hemostatic } \\
\text { (improvement of clotting rate) }\end{array}$ & $\begin{array}{l}\text { Biocompatibility } \\
\text { Time for shape recovery } \\
\text { and mechanical } \\
\text { properties compatible } \\
\text { with the therapeutic } \\
\text { site/goal } \\
\text { Possible sterilization }\end{array}$ & $\begin{array}{l}\text { Stability at relatively high } \\
\text { temperature and quick shape } \\
\text { recovery enabling suitability } \\
\text { for the battlefield } \\
\text { High porosity } \\
\text { Biocompatibility } \\
\text { Possibility of fine-tuning the } \\
\text { foam performance based on } \\
\text { the chemical structure of the } \\
\text { polymer }\end{array}$ & $\begin{array}{l}\text { High porosity } \\
\text { Biocompatibility } \\
\text { Shape memory effect also } \\
\text { influences the release kinetics } \\
\text { One-step production process, } \\
\text { easy to scale }\end{array}$ & $\begin{array}{l}\text { High porosity } \\
\text { Biocompatibility } \\
\text { Prolonged drug release obtained } \\
\text { with the multilayer design } \\
\text { One-step production process, easy } \\
\text { to scale }\end{array}$ \\
\hline Research level & $\begin{array}{l}\text { Design concept and preliminary } \\
\text { in vitro studies }\end{array}$ & $\begin{array}{l}\text { Design concept and } \\
\text { preliminary in vitro } \\
\text { studies }\end{array}$ & $\begin{array}{l}\text { Design concept and } \\
\text { preliminary in vitro studies }\end{array}$ & $\begin{array}{l}\text { Design concept and preliminary } \\
\text { in vitro and in vivo (mice) } \\
\text { studies }\end{array}$ & $\begin{array}{l}\text { Design concept and preliminary in } \\
\text { vitro studies }\end{array}$ \\
\hline $\begin{array}{l}\text { Room for } \\
\text { improvement } \\
\text { identified by the } \\
\text { authors }\end{array}$ & - & - & - & - & - \\
\hline
\end{tabular}




\subsection{Shape recovery for ensuring removal from the target area}

Release of active ingredients in specific sites within the gastrointestinal tract has largely been pursued for the treatment of local pathologies, such as gastric ulcers or inflammatory bowel disease that affects the colonic region [151-159]. However, the possibility of increasing the DDS residence time and prolonging the release of the loaded drug in the upper gastrointestinal tract, even in the esophagus, would also be beneficial. This release mode would be particularly advantageous for active molecules i) strongly affected by pre-systemic metabolization, ii) with specific absorption windows or iii) poorly soluble as well as stable in the intestinal environment. In this respect, Babaee and co-workers took advantage of the shape memory effect of nitinol for the development of an esophageal flower-like DDS to be orally administered within a commercially available hard capsule [160]. It entailed separated arms connected to a central core by means of elastic recoil elements. These enabled the system assembly, relevant folding into a swallowable collapsed configuration and mechanical reopening inside the esophagus. The expansion of the device would allow its retention in the target area while drug-containing microneedles, attached on the external surface of the arms, would penetrate the esophageal mucosa without causing relevant perforation, thus promoting anchoring of the system and enabling drug delivery. Temperature-responsive nitinol-based springs were also added, connecting each arm to the central core. Their shape memory effect, triggered upon administration of warm liquids (i.e. in the $55-65{ }^{\circ} \mathrm{C}$ temperature range), would be responsible for effective closure of the exhausted device at the end of the performance. This way safe removal from the target area and passage of the closed system in the stomach would be ensured. Notably, the administration of warm liquids was demonstrated to generally provide the users with a satisfactory feeling, without causing either burning or harmful effects.

The DDSs proposed was rather complex and the fabrication process required a number of subsequent steps, including a prototyping phase via fused deposition modeling 3D printing followed by compression molding and other manual tasks such as welding, drilling and final assembling. The 
ability of the system to be retained and then eliminated in vivo was only preliminarily tested on sedated animals, using endoscopic guidance for placing it into the proximal esophagus.

Table 6: DDSs for which the shape recovery effect allowed the elimination from the target area

\begin{tabular}{|c|c|}
\hline References & {$[160]$} \\
\hline SMM & Commercial nitinol \\
\hline Brief description of the system & $\begin{array}{l}4 \text { arms, equipped with polymeric microneedles containing the drug at their } \\
\text { distal ends, connected to a central core through elastic L-beam-shaped recoil } \\
\text { elements and nitinol springs }\end{array}$ \\
\hline Administration route & Oral \\
\hline Temporary (administered) shape & Open flower-like shape \\
\hline Triggering stimulus & Direct heating attained by administration of warm liquids $\left(55-65^{\circ} \mathrm{C}\right)$ \\
\hline Original (recovered) shape & Closed flower-like shape \\
\hline Target area for drug release & Esophagus \\
\hline Therapeutic goal & Prolonged release of drugs in the upper gastrointestinal tract \\
\hline Loaded drug/tracer & 70-kDa dextran labeled with texas red and budesonide \\
\hline $\begin{array}{l}\text { Main advantages / Innovation } \\
\text { features }\end{array}$ & $\begin{array}{l}\text { Release in an area hard to target } \\
\text { Ultra-responsive system }\end{array}$ \\
\hline Research level & $\begin{array}{l}\text { Design concept and preliminary in vitro, ex vivo (pig esophagus samples) and } \\
\text { in vivo (pigs) studies with tracer and drug }\end{array}$ \\
\hline $\begin{array}{l}\text { Room for improvement identified by } \\
\text { the authors }\end{array}$ & Fabrication process requiring multiple steps currently done manually \\
\hline
\end{tabular}

\subsection{Shape recovery for triggering drug release}

Since their appearance on the pharmaceutical market, DDSs were intended to ensure an appropriate concentration of specific drugs to be attained at the site of interest when needed [161]. As a 
consequence, they would in principle allow to overcome limitations and avoid side effects associated with the systemic administration through different routes (e.g. ensuring high local concentrations of drugs or amounts that can be tuned for specific patient needs, enable multiple release kinetics, avoid first-pass effect). Conversely to traditional passive DDSs mainly employed so far, the use of SMMs gave the opportunity to develop innovative DDSs able to actively enable the achievement of the same objectives and the identification of new, even more challenging, targets, without resorting to other expensive active technologies such as micro electro mechanical systems [45,162]. In particular, systems for which the release performance was controlled by the shape memory effect were proposed, not only in terms of rate and site but also allowing for subsequent pulses of release. Such pulses turned out even more flexible as they could be started and ended on demand by the controlled application of the triggering stimulus. In addition, the recovery-based triggering mechanism could in some cases be remotely controlled (e.g. upon application of a radio-controlled electromagnetic field) $[45,162,163]$. The working principle of such devices potentially offers not only quite high precision drug dosing but also increased safety as the system only responds to an external suitably tuned nonmechanical stimulus [164]. To enhance the system flexibility, additional release controlling mechanisms to be coupled with the shape memory effect were also tested, for instance relying on the application of functional coatings and on the variation of the viscosity of the drug containing formulation when in contact with aqueous fluids at body temperature [163].

Triggering of drug release was more often accomplished through the use of micropumps, mainly activated by the shape memory effect of purposely-developed actuators based on SMMs [45,162]. For this reason, the devices were conceived in the form of containers (e.g. capsules, chips) hosting a more or less complex pumping system and drug-loaded reservoirs, the latter connected to the external environment through holes and valves (e.g. two-way, passive-check or thermoactive valves) $[164,165]$. In some cases, these DDSs were envisaged so that the removal of the stimulus allowed the interruption of the release. As a consequence, fine tuning of the drug delivered (even up to picometric amounts) and on demand pulsatile-release performance could be achieved, leading to good potential 
for customization [163,164]. Endoscopic capsules were also proposed, entailing a tracking ensure drug release at the right site [165].

These applications were generally characterized by a high level of engineering, already recognizable in the design of the device, often combined with innovative fabrication techniques for the pharmaceutical field, such as photolithography- or lithography-based processing, microfabrication and micromachining technology, and shared the need for using biocompatible materials, which unfortunately was not always accomplished. At the same time, dyes, water and solutions with specific pHs were used to assess the controlled release capability of the devices investigated, instead of active molecules and drug tracers.

The proof of concept for fabrication and working mechanism of the DDSs here proposed was preliminary achieved, but most of these systems still need to find a solution for many limitations, such as the control of temperature (as the increase needed for operating the device could be an issue both for stability of the drug and for the surrounding tissue), miniaturization of the components and refilling of the drug-containing reservoirs. 
Table 7: DDSs for which the shape recovery effect allowed triggering of drug release

\begin{tabular}{|c|c|c|c|c|c|}
\hline References & {$[165]$} & [162] & [164] & [45] & {$[163]$} \\
\hline SMM & Commercial nitinol & Commercial nitinol & $\begin{array}{l}\text { Purposely prepared Ni-Mn- } \\
\text { Ga alloy }\end{array}$ & Commercial polyurethanes & $\begin{array}{l}\text { Purposely-synthesized poly }(\varepsilon- \\
\text { caprolactone }) \text { and oligo( } \varepsilon^{-} \\
\text {caprolactone }) \text { copolymers }\end{array}$ \\
\hline $\begin{array}{l}\text { Brief description of } \\
\text { the system }\end{array}$ & $\begin{array}{l}\text { Acrylic capsule equipped } \\
\text { with a two-way valve, } \\
\text { housing a drug-containing } \\
\text { reservoir and a wood piston } \\
\text { relying on a nitinol spring } \\
\text { actuator }\end{array}$ & $\begin{array}{l}\text { Polyimide case with a hole on the } \\
\text { top equipped with a two-way } \\
\text { valve, housing a drug-containing } \\
\text { reservoir and a microfluidic pump } \\
\text { driven by a nitinol actuator. }\end{array}$ & $\begin{array}{l}\text { 3D printed case with holes } \\
\text { housing a drug-containing } \\
\text { reservoir and pumping } \\
\text { mechanisms based on two } \\
\text { flat plates connected with } \\
\text { tubes and a cylindrical } \\
\text { rotating magnet }\end{array}$ & $\begin{array}{l}\text { Drug-containing reservoir in a } \\
\text { polymethylmethacrylate sheet } \\
\text { closed with a lid entailing a } \\
\text { planar inductor capacitor } \\
\text { circuit composed of a copper- } \\
\text { clad/polyimide planar film, } \\
\text { laminated on a shape memory } \\
\text { polymer flat actuator }\end{array}$ & $\begin{array}{l}\text { Tube-shaped container made of } \\
\text { a shape-memory polymer, } \\
\text { eventually blended with a near- } \\
\text { infrared dye, filled with a drug- } \\
\text { containing thermosensitive } \\
\text { hydrogel. The tube sides were } \\
\text { sealed by coating }\end{array}$ \\
\hline $\begin{array}{l}\text { Administration } \\
\text { route }\end{array}$ & Oral & Implantation & Implantation & Implantation & Implantation \\
\hline $\begin{array}{l}\text { Temporary } \\
\text { (administered) } \\
\text { shape }\end{array}$ & Compressed spring & $\begin{array}{l}\text { Rectangular spiral-coil shape with } \\
\text { one longitudinal end lifted up }\end{array}$ & $\begin{array}{l}\text { Flat shape with shrinkage in } \\
\text { specific areas }\end{array}$ & Cylindrical planar shape & Elongated tube shape \\
\hline Triggering stimulus & $\begin{array}{l}\text { Indirect heating via current } \\
\text { application }\end{array}$ & $\begin{array}{l}\text { Indirect heating via application of } \\
\text { radio-frequency electromagnetic } \\
\text { fields }\end{array}$ & Magnetic field & $\begin{array}{l}\text { Indirect Joule heating attained } \\
\text { via an external radio controlled } \\
\text { electromagnetic field }\end{array}$ & $\begin{array}{l}\text { Direct and indirect heating via } \\
\text { near infrared light absorption }\end{array}$ \\
\hline $\begin{array}{l}\text { Original } \\
\text { (recovered) shape }\end{array}$ & Elongated spring & Flat rectangular spiral-coil shape & Flat shape & Cylindrical lifted shape & Tube shape \\
\hline $\begin{array}{l}\text { Target area for } \\
\text { drug release }\end{array}$ & $\begin{array}{l}\text { Any area of the } \\
\text { gastrointestinal tract }\end{array}$ & Bones & Animal brain & $\begin{array}{l}\text { General (no identification of a } \\
\text { specific area of implantation) }\end{array}$ & $\begin{array}{l}\text { Regeneration of tissues } \\
\text { involved in surgical operations }\end{array}$ \\
\hline
\end{tabular}




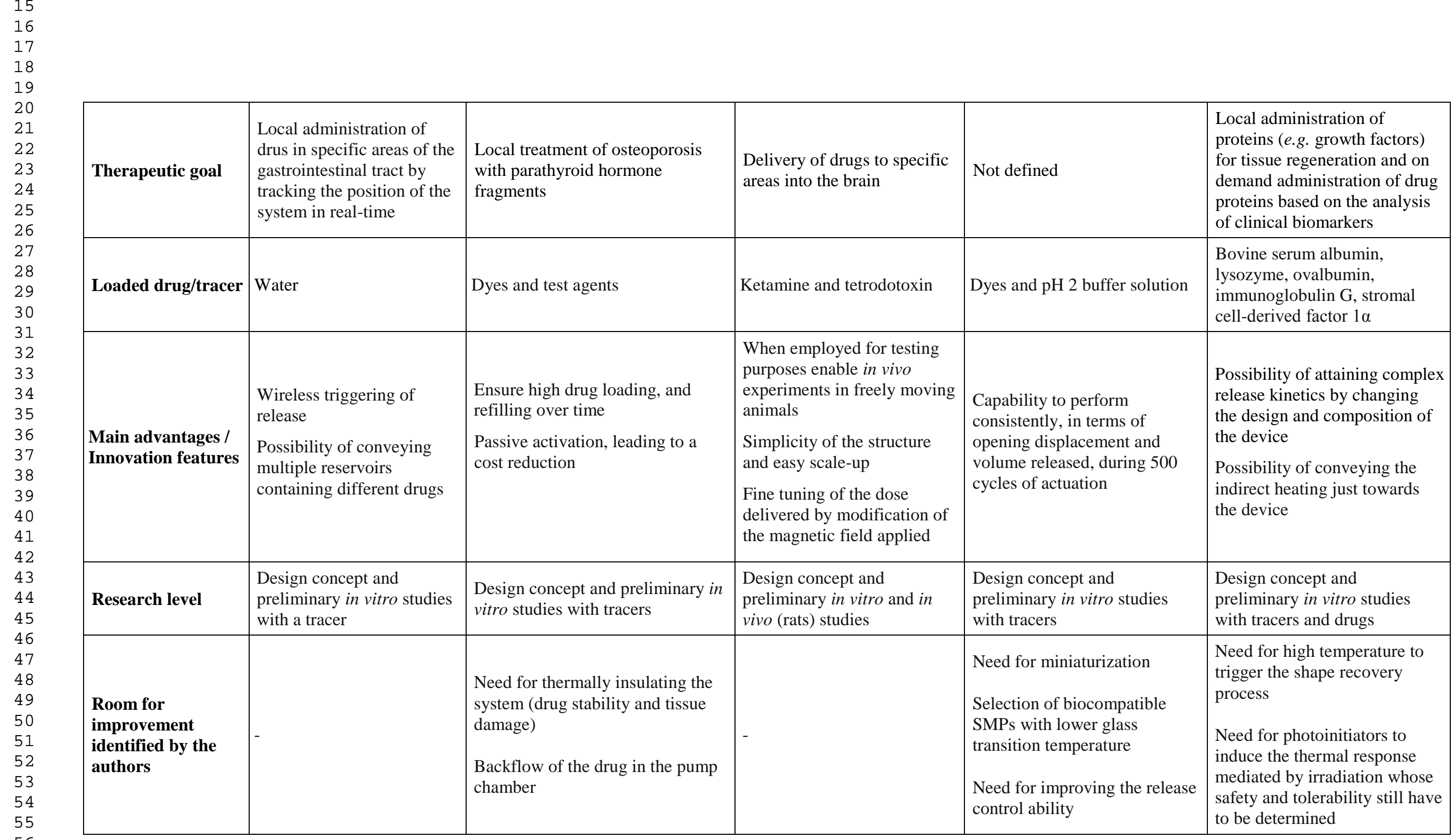




\section{Conclusions}

In the last few decades, materials science has witnessed incredible progress, which has positively influenced all sectors of industry. In this respect, SMMs, with their ability to dynamically respond to specific environmental stimuli by modifying the relevant shape over time, have just begun to show their application potential in the biomedical and pharmaceutical fields. Moreover, the use of these intelligent materials together with the recent development of 3D printing technologies will provide a tool for 4D printing implementation, leading to further benefits in terms of personalization of therapy. Within this review, we considered the overall applications of SMPs and SMAs in pharmaceutics and more specifically their use in DDS design, trying to highlight the state of the art in the field of shape memory-based and 4D printed drug products. The systems reviewed turned out to be at a rather limited degree of development, in terms of actual production (e.g. manual manufacturing, lab-scale synthesis of materials) and relevant scalability, as well as in the identification of specific therapeutic objectives, also including feasibility of administration and relevant safety. However, based on a shape memory effect well-refined and tailored through an advanced design concept, such DDSs seemed very promising, which means in principle able to provide innovative performance and to overcome many limitations of the current therapeutic strategies (e.g. poor patient compliance or adherence, ability to ensure therapeutic drug levels at the site of action for a prolonged period of time, fine tuning and customization of the performance in terms of time and site of release). The evolution of the shape over time has been sought to adapt to different needs, such as reaching, enabling retention into and ensuring removal from the target area or triggering the release of the active molecule itself. Shape memory-based DDSs were proposed for oral administration, injection or implantation, topical application and intra-organ (e.g. into the bladder and vagina) insertion. Their feasibility and further development have taken advantage of and will further benefit from the remarkable technological advances we are currently experiencing in many fields, which have led to the spread of 3D printing, electrospinning and complex microfabrication techniques. 
The main challenge for the next years remains that of their introduction into the clinical practice, especially considering that most of the materials employed are new and purposely synthetized. In this respect, the adoption of shape memory-based DDSs might be strongly supported by the growing interest in precision dosing, but the development of materials and production processes allowing stringent quality and safety requirements to be met would need to be pursued.

\section{References}

1. H.J. Huang, Y.L. Tsai, S.H. Lin, S.H. Hsu, Smart polymers for cell therapy and precision medicine, J. Biomed. Sci. 26 (2019) 1-11. https://doi.org/10.1186/s12929-019-0571-4.

2. A. Jain, S.P. Ong, G. Hautier, W. Chen, W.D. Richards, S. Dacek, D. Gunter, D. Skinner, G. Ceder, K.A. Persson, A. Jain, P. Ong, G. Hautier, W. Chen, D. Gunter, D. Skinner, G. Ceder, K.A. Persson, The Materials project: a materials genome approach to accelerating materials innovation, APL Materials. 1 (2013) 011002. https://doi.org/10.1063/1.4812323.

3. W.M. Huang, Z. Ding, C.C. Wang, J. Wei, Y. Zhao, H. Purnawali, Shape memory materials, Mater. Today. 13 (2010) 54-61. https://doi.org/10.1016/S1369-7021(10)70128-0.

4. W.M. Huang, C.L. Song, Y.Q. Fu, C.C. Wang, Y. Zhao, H. Purnawali, H.B. Lu, C. Tang, Z. Ding, J.L. Zhang, Shaping tissue with shape memory materials, Adv. Drug Deliv. Rev. 65 (2013) 515-535. https://doi.org/10.1016/j.addr.2012.06.004.

5. W. Zhao, L. Liu, F. Zhang, J. Leng, Y. Liu, Shape memory polymers and their composites in biomedical applications, Mater. Sci. Eng. C. $97 \quad$ (2019) 864-883. https://doi.org/10.1016/j.msec.2018.12.054.

6. D.C. Lagoudas Ed., Shape memory alloys - Modeling and engineering applications, Springer (2013), New York, US-NY.

7. A. Lendlein Ed., Shape-memory polymers, Springer (2010), New York, US-NY.

8. A. Lendlein, R. Langer, Biodegradable, elastic shape-memory polymers for potential biomedical applications,

Science.

296

(2002)

1673-1676. 
https://doi.org/10.1126/science.1066102.

9. V.L. Junior, V. Ste, M.A. Savi Eds, Dynamics of smart systems and structures, Springer (2010), New York, US-NY.

10. S. Kamila, Introduction, classification and applications of smart materials: an overview, Am. J. Appl. Sci. 10 (2013) 876-880. https://doi.org/10.3844/ajassp.2013.876.880.

11. R. Dhanasekaran, S.R. S, G.K. B, A.S. Anirudh, Shape memory materials for bio-medical and aerospace applications, Mater. Today Proc. 5 (2018) 21427-21435. https://doi.org/10.1016/j.matpr.2018.06.551

12. https://www.acumenresearchandconsulting.com/shape-memory-polymer-market, last access on December 4, 2020.

13. https://www.globenewswire.com/news-release/2019/06/13/1868119/0/en/Shape-MemoryPolymers-Market-Size-Worth-USD-1-84-bn-by-2026.html, last access on December 4, 2020.

14. T. Omori, R. Kainuma, Alloys with long memories, Nature. 502 (2013) 42-44. https://doi.org/10.1038/502042a

15. Z.G. Wei, Sandstroröm R., M. S., Shape-memory materials and hybrid composites for smart systems Part I Shape-memory materials, J. Mater. Sci. 3 (1998) 3743-3762.

16. L. Petrini, F. Migliavacca, Biomedical applications of shape memory alloys, J. Metall. (2011) 501483. https://doi.org/10.1155/2011/501483.

17. A. Biesiekierski, J. Wang, M. Abdel-Hady Gepreel, C. Wen, A new look at biomedical Tibased shape memory alloys, Acta Biomater. 8 (2012) 1661-1669. https://doi.org/10.1016/j.actbio.2012.01.018.

18. R. Chakraborty, M.S. Raza, S. Datta, P. Saha, Synthesis and characterization of nickel free titanium-hydroxyapatite composite coating over nitinol surface through in-situ laser cladding and alloying, $\quad$ Surf. Coat. Technol. $358 \quad$ (2019) 539-550. https://doi.org/10.1016/j.surfcoat.2018.11.036.

19. J.V.A.N. Humbeeck, Biocompatibility of Nitinol for biomedical applications, Chapter 9, pagg. 
194-233, in: T. Yoneyama, S. Miyazaki Eds., Woodhead Publishing Series in Biomaterials (2009). Cambridge UK. https://doi.org/10.1533/9781845695248.1.194.

20. E.O. Nasakina, M.A. Sudarchikova, K. V Sergienko, S. V Konushkin, M.A. Sevost, Ion release and surface characterization of nanostructured nitinol during long-term testing, Nanomater. 9 (2019) 1569. https://doi.org/10.3390/nano9111569.

21. A. Biscarini, G. Mazzolai, A. Tuissi, Enhanced nitinol properties for biomedical applications, Recent Pat. Biomed. Eng. (2008) 180-196. https://doi.org/10.2174/1874764710801030180.

22. H.F. Li, K.J. Qiu, F.Y. Zhou, L. Li, Y.F. Zheng, Design and development of novel antibacterial Ti-Ni-Cu shape memory alloys for biomedical application, Sci. Rep. 6 (2016) 1-11. https://doi.org/10.1038/srep37475.

23. I.M. Ihálcz, Fundamental characteristics and design method for nickel-titanium shape memory alloy, Periodica Polytechnica Ser. Mech. Eng. 45 (2001) 75-86.

24. S. Miyazaki, Martensitic transformation in TiNi alloys. Chapter 3, pagg. $73-87$ in: S. Miyazaki, F. Shuichi, Y. Qing, H. Wei Min Eds., Thin film shape memory alloys - Fundamentals and device applications. (2010). https://doi.org/10.1017/CBO9780511635366.004

25. C. Naresh, P.S.C. Bose, C.S. Rao, Shape memory alloys: a state of art review, IOP Conf. Ser. Mater. Sci. Eng. 149 (2016) 012054. https://doi.org/10.1088/1757-899X/149/1/012054.

26. N. Sabahi, W. Chen, C. Wang, J.J. Kruzic, X. Li, A Review on additive manufacturing of shapememory materials for biomedical applications, JOM. 72 (2020) 1229-1253. https://doi.org/10.1007/s11837-020-04013-x.

27. L. Sun, W.M. Huang, Nature of the multistage transformation in shape memory alloys upon heating, Met. Sci. Heat. Treat. 51 (2009) 573-578.

28. C.M. Wells, M. Harris, L. Choi, V.P. Murali, F.D. Guerra, J.A. Jennings, Stimuli-responsive drug release from smart polymers, J. Funct. Biomater. 10 (2019). https://doi.org/10.3390/jfb10030034.

29. F. Auricchio, E. Boatti, M. Conti, SMA Biomedical Applications. Chapter 11, pagg. 307-341, 
in: Shape memory alloy engineering for aerospace, structural and biomedical applications, L.

Lecce, A. Concilio Eds., Elsevier, 2015, Oxford UK. https://doi.org/10.1016/B978-0-08099920-3.00011-5.

30. G. Rees Douglas, Design of stent expansion mechanism, Master thesis in applied science, 2012.

31. A.F. Saleeb, B. Dhakal, J.S. Owusu-Danquah, On the role of SMA modeling in simulating NiTinol self-expanding stenting surgeries to assess the performance characteristics of mechanical and thermal activation schemes, J. Mech. Behav. Biomed. Mater. 49 (2015) 43-60. https://doi.org/10.1016/j.jmbbm.2015.04.012.

32. T. Schmidt, J. Abbott, Coronary Stents: History, Design, and Construction, J. Clin. Med. 7 (2018) 126. https://doi.org/10.3390/jcm7060126.

33. M. Shaikh, G. Kichenadasse, N.R. Choudhury, R. Butler, S. Garg, Non-vascular drug eluting stents as localized controlled drug delivery platform: Preclinical and clinical experience, J. Control. Release. 172 (2013) 105-117. https://doi.org/10.1016/j.jconrel.2013.08.010

34. H. Lee, M.J. Cima, An intravesical device for the sustained delivery of lidocaine to the bladder, J. Control. Release. 149 (2011) 133-139. https://doi.org/10.1016/j.jconrel.2010.10.016.

35. M. Reeves, B. Katz, J. Canela, M. Hathaway, M. Tal, Initial evaluation of a novel nitinol, lowdose-copper intrauterine contraceptive, $\quad$ Contraception. $90 \quad$ (2014) 315. https://doi.org/10.1016/j.contraception.2014.05.079.

36. D.K. Turok, A.L. Nelson, C. Dart, C.A. Schreiber, K. Peters, M.J. Schreifels, B. Katz, Efficacy, Safety, and Tolerability of a New Low-Dose Copper and Nitinol Intrauterine Device: Phase 2 Data to 36 Months, Obstet. Gynecol. $135 \quad$ (2020) 840-847. https://doi.org/10.1097/AOG.0000000000003756.

37. D.K. Turok, L.M. Gawron, S. Lawson, New developments in long-acting reversible contraception: the promise of intrauterine devices and implants to improve family planning services, Fertil. Steril. 106 (2016) 1273-1281. https://doi.org/10.1016/j.fertnstert.2016.09.034. 
38. M. Verma, K. Vishwanath, F. Eweje, N. Roxhed, T. Grant, M. Castaneda, C. Steiger, H. Mazdiyasni, T. Bensel, D. Minahan, V. Soares, J.A.F. Salama, A. Lopes, K. Hess, C. Cleveland, D.J. Fulop, A. Hayward, J. Collins, S.M. Tamang, T. Hua, C. Ikeanyi, G. Zeidman, E. Mule, S. Boominathan, E. Popova, J.B. Miller, A.M. Bellinger, D. Collins, D. Leibowitz, S. Batra, S. Ahuja, M. Bajiya, S. Batra, R. Sarin, U. Agarwal, S.D. Khaparde, N.K. Gupta, D. Gupta, A.K. Bhatnagar, K.K. Chopra, N. Sharma, A. Khanna, J. Chowdhury, R. Stoner, A.H. Slocum, M.J. Cima, J. Furin, R. Langer, G. Traverso, A gastric resident drug delivery system for prolonged gram-level dosing of tuberculosis treatment, Sci. Transl. Med. 11 (2019). https://doi.org/10.1126/scitranslmed.aau6267

39. G.I. Peterson, A. V. Dobrynin, M.L. Becker, Biodegradable shape memory polymers in medicine, Adv. Healthc. Mater. 6 (2017) 1-16. https://doi.org/10.1002/adhm.201700694

40. W. Sokolowski, A. Metcalfe, S. Hayashi, L. Yahia, J. Raymond, Medical applications of shape memory polymers, Biomed. Mater. 2 (2007). https://doi.org/10.1088/1748-6041/2/1/S04.

41. H. Meng, G. Li, A review of stimuli-responsive shape memory polymer composites, Polymer. 54 (2013) 2199-2221. https://doi.org/10.1016/j.polymer.2013.02.023.

42. M. Bao, Q. Zhou, W. Dong, X. Lou, Y. Zhang, Ultrasound-modulated shape memory and payload release effects in a biodegradable cylindrical rod made of chitosan-functionalized PLGA microspheres, $\quad$ Biomacromolecules. $14 \quad$ (2013) 1971-1979. https://doi.org/10.1021/bm4003464.

43. M. Behl, M.Y. Razzaq, A. Lendlein, Multifunctional shape-memory polymers, Adv. Mater. 22 (2010) 3388-3410. https://doi.org/10.1002/adma.200904447.

44. G. Li, G. Fei, H. Xia, J. Han, Y. Zhao, Spatial and temporal control of shape memory polymers and simultaneous drug release using high intensity focused ultrasound, J. Mater. Chem. 22 (2012) 7692-7696. https://doi.org/10.1039/c2jm30848g. 
45. M.A. Zainal, A. Ahmad, M.S. Mohamed Ali, Frequency-controlled wireless shape memory polymer microactuator for drug delivery application, Biomed. Microdevices. 19 (2017) 1-10. https://doi.org/10.1007/s10544-017-0148-5.

46. A.W. Basit, S. Gaisford Eds., 3D Printing of pharmaceuticals, Springer, Cham CH (2018).

47. W. Jamróz, J. Szafraniec, M. Kurek, R. Jachowicz, 3D Printing in pharmaceutical and medical applications - recent achievements and challenges, Pharm. Res. 35 (2018) 176. https://doi.org/10.1007/s11095-018-2454-X

48. V.R. Kallakunta, S. Sarabu, S. Bandari, H. Patil, M.A. Repka, An update on the contribution of hot-melt extrusion technology to novel drug delivery in the twenty-first century: part I, Expert Opin. Drug Deliv. 16 (2019) 539-550. https://doi.org/10.1080/17425247.2019.1609448.

49. A. Melocchi, M. Uboldi, M. Cerea, A. Foppoli, A. Maroni, S. Moutaharrik, L. Palugan, L. Zema, A. Gazzaniga, A graphical review on the escalation of fused deposition modeling (FDM) 3D printing in the pharmaceutical field, J. Pharm. Sci. 109 (2020) 2943-2957. https://doi.org/10.1016/j.xphs.2020.07.011.

50. A. Melocchi, F. Briatico-vangosa, M. Uboldi, M. Turchi, D. Von Zeppelin, A. Maroni, A. Gazzaniga, A. Zidan, Quality considerations on the pharmaceutical applications of fused deposition modeling 3D printing, Int. J. Pharm. (2020) 119901. https://doi.org/10.1016/j.ijpharm.2020.119901

51. A. Melocchi, M. Uboldi, A. Maroni, A. Foppoli, L. Palugan, L. Zema, A. Gazzaniga, 3D printing by fused deposition modeling of single- and multi-compartment hollow systems for oral delivery - $\quad$ A review, Int. J. Pharm. $579 \quad$ (2020) 119155. https://doi.org/10.1016/j.ijpharm.2020.119155

52. S. Sarabu, S. Bandari, V.R. Kallakunta, H. Patil, M.A. Repka, An update on the contribution of hot-melt extrusion technology to novel drug delivery in the twenty-first century: part II, Expert Opin. Drug Deliv. 16 (2019) 567-582. https://doi.org/10.1080/17425247.2019.1614912. 
53. G. Loreti, A. Maroni, M.D. Del Curto, A. Melocchi, A. Gazzaniga, L. Zema, Evaluation of hotmelt extrusion technique in the preparation of HPC matrices for prolonged release, Eur. J. Pharm. Sci. 52 (2014) 77-85. https://doi.org/10.1016/j.ejps.2013.10.014.

54. L. Zema, G. Loreti, A. Melocchi, A. Maroni, A. Gazzaniga, Injection Molding and its application to drug delivery, J. Control. Release 159 (2012) 324-331. https://doi.org/10.1016/j.jconrel.2012.01.001.

55. L. Zema, A. Melocchi, A. Maroni, A. Gazzaniga, Three-dimensional printing of medicinal products and the challenge of personalized therapy, J. Pharm. Sci. 106 (2017) 1697-1705. https://doi.org/10.1016/j.xphs.2017.03.021

56. A. Lendlein, S. Kelch, Shape-Memory Polymers A, Angew. Chem. Int. Ed. Engl. 41 (2002) 2034-2057. https://doi.org/10.1002/1521-3773(20020617)41:12<2034::aidanie2034>3.0.co;2-m

57. M.C. Serrano, G.A. Ameer, Recent insights into the biomedical applications of shape-memory polymers, Macromol. Biosci. 12 (2012) 1156-1171. https://doi.org/10.1002/mabi.201200097.

58. W.M. Huang, Y. Zhao, C.C. Wang, Z. Ding, Thermo/chemo-responsive shape memory effect in polymers: a sketch of working mechanisms, fundamentals and optimization, J Polym. Res. 19 (2012) 9952. https://doi.org/10.1007/s10965-012-9952-z.

59. Z. Jiang, Y. Xiao, Y. Kang, M. Pan, B. Li, S. Zhang, Shape memory polymers based on supramolecular interactions, CS Appl. Mater. Interfaces 9 (2017) 20276-20293. https://doi.org/10.1021/acsami.7b03624.

60. Y. Xia, Y. He, F. Zhang, Y. Liu, J. Leng, A review of shape memory polymers and composites: mechanisms, Adv. Mater. (2020) 2000713. https://doi.org/10.1002/adma.202000713.

61. M. Balk, M. Behl, C. Wischke, J. Zotzmann, A. Lendlein, Recent advances in degradable lactide-based shape-memory polymers, Adv. Drug Deliv. Rev. 107 (2016) 136-152. https://doi.org/10.1016/j.addr.2016.05.012. 
62. M.D. Hager, S. Bode, C. Weber, U. S. Schubert, Shape memory polymers: Past, present and future developments, Prog. Polym. Sci. 49-50 (2015) 30-33. https://doi.org/10.1016/j.progpolymsci.2015.04.002.

63. A. Lendlein, M. Behl, B. Hiebl, C. Wischke, Shape-memory polymers as a technology platform for biomedical applications, Expert Rev. Med. Devices. 7 (2010) 357-379. https://doi.org/10.1586/erd.10.8.

64. C. Wischke, A. Lendlein, Shape-memory polymers as drug carriers-a multifunctional system, Pharm. Res. 27 (2010) 527-529. https://doi.org/10.1007/s11095-010-0062-5.

65. R. Liang, L. Wang, H. Yu, A. Khan, B. Ul Amin, R.U. Khan, Molecular design, synthesis and biomedical applications of stimuli-responsive shape memory hydrogels, Eur. Polym. J. 114 (2019) 380-396. https://doi.org/10.1016/j.eurpolymj.2019.03.004.

66. H. Lu, J. Leng, S. Du, A phenomenological approach for the chemo- responsive shape memory effect in amorphous polymers, Soft Matter 9 (2013) 3851-3858. https://doi.org/10.1039/c3sm27539f.

67. H. Lu, W.M. Huang, Chemo-responsive shape-memory polymers for biomedical applications, Chapter 6, pagg. 99-132, in: L. Yahia Ed., Shape memory polymers for biomedical applications, Woodhead Publishing Series in Biomaterials, Elsevier (2015), Cambridge, UK. https://doi.org/10.1016/B978-0-85709-698-2.00006-4.

68. C.L. Lewis, E.M. Dell, A review of shape memory polymers bearing reversible binding groups, J. Polym. Sci. B Polym. Phys. 54 (2016) 1340-1364. https://doi.org/10.1002/polb.23994.

69. S.L. Buffington, J.E. Paul, M.M. Ali, M.M. Macios, P.T. Mather, J.H. Henderson, Enzymatically triggered shape memory polymers, Acta Biomater. 84 (2019) 88-9. https://doi.org/10.1016/j.actbio.2018.11.031.

70. B.Q.Y. Chan, Z.W.K. Low, S.J.W. Heng, S.Y. Chan, C. Owh, X.J. Loh, Recent advances in shape memory soft materials for biomedical applications, ACS Appl. Mater. Interfaces. 8 (2016) 10070-10087. https://doi.org/10.1021/acsami.6b01295. 
71. C. Wischke, M. Behl, A. Lendlein, Drug-releasing shape-memory polymers-the role of morphology, processing effects, and matrix degradation, Expert Opin. Drug Deliv. 10 (2013) 1193-1205. https://doi.org/10.1517/17425247.2013.797406.

72. Y. Wu, L. Wang, X. Zhao, S. Hou, B. Guo, P.X. Ma, Self-healing supramolecular bioelastomers with shape memory property as a multifunctional platform for biomedical applications via modular $\quad$ assembly, $\quad$ Biomaterials. $\quad 104 \quad$ (2016) https://doi.org/10.1016/j.biomaterials.2016.07.011.

73. D.L. Safranski, K.E. Smith, K. Gall, Mechanical requirements of shape-memory polymers in biomedical devices, $\quad$ Polym. Rev. $53 \quad$ (2013) 76-91. https://doi.org/10.1080/15583724.2012.752385.

74. M.C. Serrano, L. Carbajal, G.A. Ameer, Novel biodegradable shape-memory elastomers with drug-releasing capabilities, Adv. Mater. $23 \quad$ (2011) 2211-2215. https://doi.org/10.1002/adma.201004566.

75. Y. Feng, S. Zhang, H. Wang, H. Zhao, J. Lu, J. Guo, M, Behl, A. Lendlein, Drug release from biodegradable polyesterurethanes with shape-memory effect. J. Control. release 152 (2011) e20-21, https://doi.org/doi:10.1016/j.jconrel.2011.08.097.

76. M. Kashif, B.M. Yun, K.S. Lee, Y.W. Chang, Biodegradable shape-memory poly( $(\varepsilon-$ caprolactone)/polyhedral oligomeric silsequioxane nanocomposites: Sustained drug release and hydrolytic degradation, Mater. Lett. $166 \quad$ (2016) 125-128. https://doi.org/10.1016/j.matlet.2015.12.051.

77. A.T. Neffe, B.D. Hanh, S. Steuer, A. Lendlein, Polymer networks combining controlled drug release, biodegradation, and shape memory capability, Adv. Mater. 21 (2009) 3394-3398. https://doi.org/10.1002/adma.200802333.

78. A. Neffe, H. Bui, S. Steuer, C. Wischke, A. Lendlein, Thermoemechanical properties and shape-memory capability of drug loaded semi- crystalline polyestermethacrylate networks, 
Mater. Res. Soc. Symp. Proc., 1144 (2009) 1144-LL16-04. https://doi.org/10.1557/PROC1144-LL16-04.

79. C. Wischke, A.T. Neffe, S. Steuer, A. Lendlein, Comparing techniques for drug loading of shape-memory polymer networks - effect on their functionalities, Eur. J. Pharm. Sci. 41 (2010) 136-147. https://doi.org/10.1016/j.ejps.2010.06.003.

80. C. de Marco, C.C.J. Alcântara, S. Kim, F. Briatico, A. Kadioglu, G. de Bernardis, X. Chen, C. Marano, B.J. Nelson, S. Pané, Indirect 3D and 4D Printing of Soft Robotic Microstructures, Adv. Mater. Technol. 4 (2019) 1-7. https://doi.org/10.1002/admt.201900332.

81. J. Firth, S. Gaisford, A.W. Basit, A new dimension: 4D printing opportunities in pharmaceutics, AAPS Adv. Pharm. Sci. Ser. 31 (2018) 153-162. https://doi.org/10.1007/978-3-319-907550_8.

82. Y.S. Lui, W.T. Sow, L.P. Tan, Y. Wu, Y. Lai, H. Li, 4D printing and stimuli-responsive materials in biomedical aspects, Acta Biomater. 92 (2019) 19-36. https://doi.org/10.1016/j.actbio.2019.05.005.

83. I. Lukin, S. Musquiz, I. Erezuma, T.H. Al-Tel, N. Golafshan, A. Dolatshahi-Pirouz, G. Orive, Can 4D bioprinting revolutionize drug development?, Expert Opin. Drug Discov. 14 (2019) 953-956. https://doi.org/10.1080/17460441.2019.1636781.

84. S. Tibbits, 4D Printing, Archit. Des. $84 \quad$ (2014) 116-121. https://doi.org/10.1142/9789811201493_0027.

85. S.J. Trenfield, A. Awad, C.M. Madla, G.B. Hatton, J. Firth, A. Goyanes, S. Gaisford, A.W. Basit, Shaping the future: recent advances of 3D printing in drug delivery and healthcare, Expert Opin. Drug Deliv. 16 (2019) 1081-1094. https://doi.org/10.1080/17425247.2019.1660318.

86. L. Ionov, 4D Biofabrication: Materials, Methods, and Applications, Adv. Healthc. Mater. 7 (2018) 1-14. https://doi.org/10.1002/adhm.201800412.

87. X. Li, J. Shang, Z. Wang, Intelligent materials: A review of applications in 4D printing, Assem. Autom. 37 (2017) 170-185. https://doi.org/10.1108/AA-11-2015-093. 
88. G.H. Yang, M. Yeo, Y.W. Koo, G.H. Kim, 4D Bioprinting: technological advances in biofabrication, Macromol. Biosci. 19 (2019) 1-10. https://doi.org/10.1002/mabi.201800441.

89. Z. Zhang, K.G. Demir, G.X. Gu, Developments in 4D-printing: a review on current smart materials, technologies, and applications, Int. J. Smart Nano Mater. 10 (2019) 205-224. https://doi.org/10.1080/19475411.2019.1591541.

90. Y. Zhou, W.M. Huang, S.F. Kang, X.L. Wu, H.B. Lu, J. Fu, H. Cui, From 3D to 4D printing: approaches and typical applications, J. Mech. Sci. Technol. 29 (2015) 4281-4288. https://doi.org/10.1007/s12206-015-0925-0.

91. B. Gao, Q. Yang, X. Zhao, G. Jin, Y. Ma, F. Xu, 4D Bioprinting for Biomedical Applications, Trends Biotechnol. 34 (2016) 746-756. https://doi.org/10.1016/j.tibtech.2016.03.004.

92. J.J. Wu, L.M. Huang, Q. Zhao, T. Xie, 4D Printing: History and Recent Progress, Chinese J. Polym. Sci. (English Ed. 36 (2018) 563-575. https://doi.org/10.1007/s10118-018-2089-8.

93. M. Zafar, H. Zhao, 4D Printing: future insight in additive manufacturing, Met. Mater. Int. 26, (2020) 564-585. https://doi.org/10.1007/s12540-019-00441-w

94. M.A. Alhnan, T.C. Okwuosa, M. Sadia, K. Wan, W. Ahmed, Emergence of 3D printed dosage forms: opportunities and challenges, Pharm. Res. 33 (2016) 1817-1832. https://doi.org/10.1007/s11095-016-1933-1.

95. A. Awad, S.J. Trenfield, A. Goyanes, S. Gaisford, A.W. Basit, Reshaping drug development using 3D printing, Drug Discov. Today 23 (2018) 1547-1555. https://doi.org/10.1016/j.drudis.2018.05.025.

96. A. Melocchi, M. Uboldi, F. Parietti, M. Cerea, A. Foppoli, L. Palugan, A. Gazzaniga, A. Maroni, L. Zema, Lego-Inspired Capsular Devices for the Development of Personalized Dietary Supplements: Proof of Concept With Multimodal Release of Caffeine, J. Pharm. Sci., 109 (2020) 1990-1999, https://doi.org/10.1016/j.xphs.2020.02.013. 
97. L.K. Prasad, H. Smyth, L.K. Prasad, H. Smyth, 3D Printing Technologies for Drug Delivery: A Review, Drug Discov. Today $9045 \quad$ (2015) 1019-1031. https://doi.org/10.3109/03639045.2015.1120743.

98. G.R., Gameiro, V. Sinkunas, GL. Liguori, J.O-Ccauler-Junior. Precision Medicine: changing the way we think about healthcare. Clinics 73 (2018) e723. http://doi.org/10.6061/clinics/2017/e723.

99. G.S. Ginsburg, K.A. Phillips, Precision medicine: from science to value, Value. Health Affairs 37 (2018) 694-701. http://doi.org/10.1377/hlthaff.2017.1624.

100. L.H. Goetz, N.J. Schork, Personalized medicine: motivation, challenges, and progress. Fertil. Steril. 109 (2018):952-963. http://doi.org/10.1016/j.fertnstert.2018.05.006.

101. D. Ho, S.R. Quake, E.R.B. McCabe, W.J. Chng, E.K. Chow, X. Ding, B.D. Gelb, G.S. Ginsburg, J. Hassenstab, C.M. Ho, W.C. Mobley, G.P. Nolan, S.T. Rosen, P. Tan, Y. Yen, A. Zarrinpar, Enabling Technologies for Personalized and Precision Medicine, Trends Biotechnol. 38 (2020) 497-518. https://doi.org/10.1016/j.tibtech.2019.12.021.

102. W.K. Redekop, D. Mladsi, The faces of personalized medicine: a framework for understanding its meaning and scope. Value Health. 16 (2013) S4-9. https://doi.org/10.1016/j.jval.2013.06.005. PMID: 24034312.

103. C. Sarisozen, G. Salzano, V.P. Torchilin, Recent advances in siRNA delivery, Biomol. Concepts. 6 (2015) 321-341. https://doi.org/10.1515/bmc-2015-0019.

104. A.A. Seyhan, C. Carini, Are innovation and new technologies in precision medicine paving a new era in patients centric care?, J. Transl. Med. 17 (2019) 1-28. https://doi.org/10.1186/s12967-019-1864-9.

105. A. Subhan, V.P. Torchilin, siRNA based drug design, quality, delivery and clinical translation, Nanomedicine. 29 (2020) 102239. https://doi.org/10.1016/j.nano.2020.102239.

106. R. Tang, Z. Xu, Gene therapy: a double-edged sword with great powers, Mol. Cell. Biochem. 474 (2020) 73-81. https://doi.org/10.1007/s11010-020-03834-3. 
107. X. Wu, T. Wu, J. Liu, B. Ding, Gene Therapy Based on Nucleic Acid Nanostructure, Adv. Healthc. Mater. 9 (2020) 1-10. https://doi.org/10.1002/adhm.202001046.

108. J. Lin, G.E. Sklar, V.M. Sen Oh, S.C. Li, Factors affecting therapeutic compliance: A review from the patient's perspective, Ther. Clin. Risk Manag. 4 (2008) 269-286. https://doi.org/10.2147/tcrm.s1458.

109. B. Steward, Compliance, Adherence and Concordance: A Review of Engaging Patients in their Treatment, Br. J. Hand Ther. 9 (2004) 88-95. https://doi.org/10.1177/175899830400900302.

110. T. Walters-Salas, The challenge of patient adherence, Bariatr. Nurs. Surg. Patient Care. 7 (2012) 186. https://doi.org/10.1089/bar.2012.9960.

111. S. Kelch, S. Steuer, A.M. Schmidt, A. Lendlein, Shape-memory polymer networks from oligo[( $\varepsilon$-hydroxycaproate)-co-glycolate $]$ dimethacrylates and butyl acrylate with adjustable hydrolic degradation rate, Biomacromolecules. $8 \quad$ (2007) 1018-1027. https://doi.org/10.1021/bm0610370.

112. K. Nagahama, Y. Ueda, T. Ouchi, Y. Ohya, Biodegradable shape-memory polymers exhibiting sharp thermal transitions and controlled drug release, Biomacromolecules. 10 (2009) 17891794. https://doi.org/10.1021/bm9002078

113. C. Wischke, A.T. Neffe, S. Steuer, A. Lendlein, Evaluation of a degradable shape-memory polymer network as matrix for controlled drug release, J. Control. Release. 138 (2009) $243-$ 250. https://doi.org/10.1016/j.jconrel.2009.05.027.

114. M. Bil, E. Kijeńska-Gawrońska, E. Głodkowska-Mrówka, A. Manda-Handzlik, P. Mrówka, Design and in vitro evaluation of electrospun shape memory polyurethanes for self-fitting tissue engineering grafts and drug delivery systems, Mater. Sci. Eng. C. 110 (2020). https://doi.org/10.1016/j.msec.2020.110675.

115. Y.K. Feng, S.F. Zhang, L. Zhang, J.T. Guo, Y.S. Xu, Release of Aspirin from Biodegradable Polyesterurethane Networks, Adv. Mater. Res. 79-82 (2009) 1431-1434. https://doi.org/10.4028/www.scientific.net/amr.79-82.1431. 
116. J. Jaworska, K. Jelonek, M. Sobota, J. Kasperczyk, P. Dobrzynski, M. Musial-Kulik, A. SmolaDmochowska, H. Janeczek, B. Jarzabek, Shape-memory bioresorbable terpolymer composite with antirestenotic drug, J. Appl. Polym. Sci. 132 (2015) 1-8. https://doi.org/10.1002/app.41902.

117. X. Li, X. Peng, R. Li, Y. Zhang, Z. Liu, Y. Huang, S. Long, H. Li, Multiple hydrogen bondsreinforced hydrogels with high strength, shape memory, and adsorption anti-inflammatory molecules, Macromol. $\quad$ Rapid Commun. $41 \quad$ (2020) 1-10. https://doi.org/10.1002/marc.202000202.

118. K.S. Lee, Y.W. Chang, Thermal and mechanical properties of poly( $\varepsilon$-caprolactone)/polyhedral oligomeric silsesquioxane nanocomposites, Polym. Int. 62 (2013) 64-70. https://doi.org/10.1002/pi.4309.

119. Y. Xu, H. Yang, H. Zhu, L. Jiang, H. Yang, Self-healing gelatin-based shape memory hydrogels via quadruple hydrogen bonding and coordination crosslinking for controlled delivery of 5fluorouracil, J. Biomater. Sci. Polym. Ed. $31 \quad$ (2020) 712-728. https://doi.org/10.1080/09205063.2020.1713711.

120. R. Zamani Alavijeh, P. Shokrollahi, J. Barzin, A thermally and water activated shape memory gelatin physical hydrogel, with a gel point above the physiological temperature, for biomedical applications, J. Mater. Chem. B. 5 (2017) 2302-2314. https://doi.org/10.1039/c7tb00014f.

121. M. Sivaperuman Kalairaj, B.S. Yeow, C.M. Lim, H. Ren, Nitinol actuated soft structures towards transnasal drug delivery: a pilot cadaver study, Med. Biol. Eng. Comput. 58 (2020) 611-623. https://doi.org/10.1007/s11517-019-02102-x.

122. H. Xuan, H. Hu, C. Geng, J. Song, Y. Shen, D. Lei, Q. Guan, S. Zhao, Z. You, Biofunctionalized chondrogenic shape-memory ternary scaffolds for efficient cell-free cartilage regeneration, Acta Biomater. 105 (2020) 97-110. https://doi.org/10.1016/j.actbio.2020.01.015.

123. L. Du, S. Yang, W. Li, H. Li, S. Feng, R. Zeng, B. Yu, L. Xiao, H.Y. Nie, M. Tu, Scaffold composed of porous vancomycin-loaded poly(lactide-co-glycolide) microspheres: A 
controlled-release drug delivery system with shape-memory effect, Mater. Sci. Eng. C. 78 (2017) 1172-1178. https://doi.org/10.1016/j.msec.2017.04.099.

124. B. Xu, Y. Li, F. Gao, X. Zhai, M. Sun, W. Lu, Z. Cao, W. Liu, high strength multifunctional multiwalled hydrogel tubes: ion-triggered shape memory, antibacterial, and anti-inflammatory efficacies, ACS Appl. Mater. Interfaces. $7 \quad$ (2015) 16865-16872. https://doi.org/10.1021/acsami.5b05074.

125. R. Dimatteo, N.J. Darling, T. Segura, In situ forming injectable hydrogels for drug delivery and wound repair, Adv. Drug Deliv. Rev. 127 (2018) 167-184. https://doi.org/10.1016/j.addr.2018.03.007.

126. W. He, M. Reaume, M. Hennenfent, B.P. Lee, R. Rajachar, Biomimetic hydrogels with spatialand temporal-controlled chemical cues for tissue engineering, Biomater. Sci. 8 (2020) 32483269. https://doi.org/10.1039/d0bm00263a.

127. H. Jo, M. Yoon, M. Gajendiran, K. Kim, Recent strategies in fabrication of gradient hydrogels for tissue engineering applications, Macromol. Biosci. 20 (2020) 1-11. https://doi.org/10.1002/mabi.201900300.

128. Y. Wang, Y. Miao, J. Zhang, J.P. Wu, T.B. Kirk, J. Xu, D. Ma, W. Xue, Three-dimensional printing of shape memory hydrogels with internal structure for drug delivery, Mater. Sci. Eng. C. 84 (2018) 44-51. https://doi.org/10.1016/j.msec.2017.11.025.

129. M.G. Mennuni, P.A. Pagnotta, G.G. Stefanini. Coronary Stents: the impact of technological advances on clinical outcomes. Ann Biomed Eng. 44 (2016):488-96. https://doi.org/10.1007/s10439-015-1399-z.

130. S.M. Shamimi-Noori, T.W.I. Clark, Venous stents: current status and future directions, Tech. Vasc. Interv. Radiol. 21 (2018) 113-116. https://doi.org/10.1053/j.tvir.2018.03.007.

131. J. Mohd Jani, M. Leary, A. Subic, M.A. Gibson, A review of shape memory alloy research, applications and opportunities, Mater. Des. $56 \quad$ (2014) 1078-1113. https://doi.org/10.1016/j.matdes.2013.11.084. 
132. H.M. Wache, D.J. Tartakowska, A. Hentrich, M.H. Wagner, Development of a polymer stent with shape memory effect as a drug delivery system, J. Mater. Sci. Mater. Med. 14 (2003) 109112. https://doi.org/10.1023/A:1022007510352.

133. M.C. Chen, H.W. Tsai, Y. Chang, W.Y. Lai, F.L. Mi, C.T. Liu, H.S. Wong, H.W. Sung, Rapidly self-expandable polymeric stents with a shape-memory property, Biomacromolecules. 8 (2007) 2774-2780. https://doi.org/10.1021/bm7004615

134. M.C. Chen, Y. Chang, C.T. Liu, W.Y. Lai, S.F. Peng, Y.W. Hung, H.W. Tsai, H.W. Sung. The characteristics and in vivo suppression of neointimal formation with sirolimus-eluting $\begin{array}{lllll}\text { polymeric } & \text { stents. } & \text { Biomaterials. } & 30 & \text { (2009) }\end{array}$ https://doi.org/10.1016/j.biomaterials.2008.09.006

135. V.C. Sonawane, M.P. More, A.P. Pandey, P.O. Patil, P.K. Deshmukh, Fabrication and characterization of shape memory polymers based bioabsorbable biomedical drug eluting stent, Artif. Cells Nanomed. Biotechnol. $45 \quad$ (2017) 1740-1750. https://doi.org/10.1080/21691401.2017.1282867.

136. C.S. Yang, H.C. Wu, J.S. Sun, H.M. Hsiao, T.W. Wang, Thermo-induced shape-memory PEGPCL copolymer as a dual-drug-eluting biodegradable stent, ACS Appl. Mater. Interfaces. 5 (2013) 10985-10994. https://doi.org/10.1021/am4032295.

137. Y. Zheng, Y. Li, X. Hu, J. Shen, S. Guo, Biocompatible shape memory blend for selfexpandable stents with potential biomedical applications, ACS Appl. Mater. Interfaces. 9 (2017) 13988-13998. https://doi.org/10.1021/acsami.7b04808.

138. L. Xue, S. Dai, Z. Li, Synthesis and characterization of elastic star shape-memory polymers as self-expandable drug-eluting stents, J. Mater. Chem. 22 (2012) 7403-7411. https://doi.org/10.1039/c2jm15918j.

139. A. Maroni, A. Melocchi, L. Zema, A. Foppoli, A. Gazzaniga, Retentive drug delivery systems based on shape memory materials, J. Appl. Polym. Sci. 137 (2020). https://doi.org/10.1002/app.48798. 
140. A. Melocchi, G. Loreti, M.D. Del Curto, A. Maroni, A. Gazzaniga, L. Zema, evaluation of hotmelt extrusion and injection molding for continuous manufacturing of immediate-release tablets, J. Pharm. Sci., 104 (2015) 1971-1980. https://doi.org/10.1002/jps.24419.

141. A. Melocchi, F. Parietti, A. Maroni, A. Foppoli, A. Gazzaniga, L. Zema, Hot-melt extruded filaments based on pharmaceutical grade polymers for 3D printing by fused deposition modeling, iNt. J. Pharm., 509 (2016) 255-263. https://doi.org/10.1016/j.ijpharm.2016.05.036.

142. A. Melocchi, N. Inverardi, M. Uboldi, F. Baldi, A. Maroni, S. Pandini, F. Briatico-Vangosa, L. Zema, A. Gazzaniga, Retentive device for intravesical drug delivery based on water-induced shape memory response of poly(vinyl alcohol): design concept and 4D printing feasibility, Int. J. Pharm. 559 (2019) 299-311. https://doi.org/10.1016/j.ijpharm.2019.01.045.

143. A. Melocchi, M. Uboldi, N. Inverardi, F. Briatico-Vangosa, F. Baldi, S. Pandini, G. Scalet, F. Auricchio, M. Cerea, A. Foppoli, A. Maroni, L. Zema, A. Gazzaniga, Expandable drug delivery system for gastric retention based on shape memory polymers: Development via 4D printing

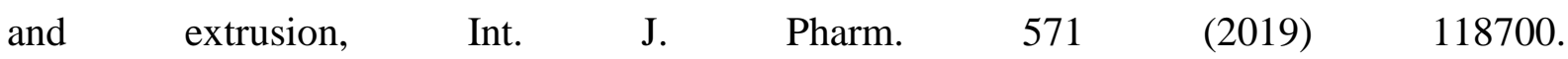
https://doi.org/10.1016/j.ijpharm.2019.118700.

144. R.S. Teller, R. Rastogi, T.J. Johnson, M.J. Blair, R.W. Hitchcock, P.F. Kiser, Intravaginal flux controlled pump for sustained release of macromolecules, Pharm. Res. 31 (2014) 2344-2353. https://doi.org/10.1007/s11095-014-1331-5.

145. L. Tan, J. Hu, H. Huang, J. Han, H. Hu, Study of multi-functional electrospun composite nanofibrous mats for smart wound healing, Int. J. Biol. Macromol. 79 (2015) 469-476. https://doi.org/10.1016/j.ijbiomac.2015.05.014.

146. J. Tang, R. Zhao, X. Yin, Y. Wen, Y. Shi, P. Zhu, Z. Chen, R. Zeng, L. Tan, Programmable release of berberine chloride hydrate from shape memory fibers prepared from core-sheath wetspinning technology. J. Biomed. Nanotechnol. $15 \quad$ (2019) 1432-1442. https://doi.org/10.1166/jbn.2019.2784. 
147. W.C. Zhou, P.F. Tan, X.H. Chen, Y. Cen, C. You, L. Tan, H. Li, M. Tian, Berberineincorporated shape memory fiber applied as a novel surgical suture, Front. Pharmacol. 10 (2020) 1-13. https://doi.org/10.3389/fphar.2019.01506.

148. X. Yin, P. Tan, H. Luo, J. Lan, Y. Shi, Y. Zhang, H. Fan, L. Tan, Study on the release behaviors of berberine hydrochloride based on sandwich nanostructure and shape memory effect, Mater. Sci. Eng. C. 109 (2020) 110541. https://doi.org/10.1016/j.msec.2019.110541.

149. S. Paonessa, N. Barbani, E.C. Rocchietti, C. Giachino, C. Cristallini, Design and development of a hybrid bioartificial water-induced shape memory polymeric material as an integral component for the anastomosis of human hollow organs, Mater. Sci. Eng. C. 75 (2017) $1427-$ 1434. https://doi.org/10.1016/j.msec.2017.03.039.

150. M.B.B. Monroe, A.D. Easley, K. Grant, G.K. Fletcher, C. Boyer, D.J. Maitland, Multifunctional shape-memory polymer foams with bio-inspired antimicrobials, ChemPhysChem. 19 (2018) 1999-2008. https://doi.org/10.1002/cphc.201701015.

151. P.L. Bardonnet, V. Faivre, W.J. Pugh, J.C. Piffaretti, F. Falson, Gastroretentive dosage forms: Overview and special case of Helicobacter pylori, J. Control. Release. 111 (2006) 1-18. https://doi.org/10.1016/j.jconrel.2005.10.031.

152. M. Cerea, A. Maroni, L. Palugan, M. Bellini, A. Foppoli, A. Melocchi, L. Zema, A. Gazzaniga. Novel hydrophilic matrix system with non-uniform drug distribution for zero-order release kinetics. J Control Release. 287 (2018) 247-256. https://doi.org/10.1016/j.jconrel.2018.08.027.

153. A. Foppoli, A. Maroni, S. Moutaharrik, A. Melocchi, L. Zema, L. Palugan, M. Cerea, A. Gazzaniga, In vitro and human pharmacoscintigraphic evaluation of an oral 5-ASA delivery system for colonic release, Int. J. Pharm., 572 (2019) 118723. https://doi.org/10.1016/j.ijpharm.2019.118723.

154. A. Maroni, L. Zema, M. Cerea, A. Foppoli, L.a Palugan, A. Gazzaniga,Erodible drug delivery systems for time-controlled release into the gastrointestinal tract, J. Drug Deliv. Sci.Technol. 32 Part B (2016)229-235. https://doi.org/10.1016/j.jddst.2015.10.001. 
155. J.F. Pinto, Site-specific drug delivery systems within the gastro-intestinal tract: from the mouth to the colon, Int. J. Pharm. 395 (2010) 44-52. https://doi.org/10.1016/j.ijpharm.2010.05.003.

156. C.M. Lopes, C. Bettencourt, A. Rossi, F. Buttini, P. Barata, Overview on gastroretentive drug delivery systems for improving drug bioavailability, Int. J. Pharm. 510 (2016) 144-158. https://doi.org/10.1016/j.ijpharm.2016.05.016.

157. R. Arévalo-Pérez, C. Maderuelo, J.M. Lanao, Recent advances in colon drug delivery systems, J. Control. Release. 327 (2020) 703-724. https://doi.org/10.1016/j.jconrel.2020.09.026.

158. N. Rouge, P. Buri, E. Doelker, Drug absorption sites in the gastrointestinal tract and dosage forms for site-specific delivery, Int. J. Pharm. 136 (1996) 117-139. https://doi.org/10.1016/0378-5173(96)85200-8.

159. A.H. Teruel, I. Gonzalez-Alvarez, M. Bermejo, V. Merino, M.D. Marcos, F. Sancenon, M. Gonzalez-Alvarez, R. Martinez-Mañez, New insights of oral colonic drug delivery systems for inflammatory bowel disease therapy, Int. J. Mol. Sci. 21 (2020) 1-30. https://doi.org/10.3390/ijms21186502.

160. S. Babaee, S. Pajovic, A.R. Kirtane, J. Shi, E. Caffarel-Salvador, K. Hess, J.E. Collins, S. Tamang, A. V. Wahane, A.M. Hayward, H. Mazdiyasni, R. Langer, G. Traverso, Temperatureresponsive biometamaterials for gastrointestinal applications, Sci. Transl. Med. 11 (2019). eaau8581. https://doi.org/10.1126/scitranslmed.aau8581.

161. K. Park, Drug delivery research: the invention cycle, Mol. Pharm. 13 (2016) 2143-2147. https://doi.org/10.1021/acs.molpharmaceut.6b00015.

162. J. Fong, Z. Xiao, K. Takahata, Wireless implantable chip with integrated nitinol-based pump for radio-controlled local drug delivery, Lab Chip. 15 (2015) 1050-1058. https://doi.org/10.1039/c4lc01290a.

163. D.C. Tuncaboylu, F. Friess, C. Wischke, A. Lendlein, A multifunctional multimaterial system for on-demand protein release, J. Control. Release. 284 (2018) 240-247. https://doi.org/10.1016/j.jconrel.2018.06.022. 
164. S. Barker, E. Rhoads, P. Lindquist, M. Vreugdenhil, P. Müllner, Magnetic shape memory micropump for submicroliter intracranial drug delivery in rats, J. Med. Devices, Trans. ASME. 10 (2016) 1-6. https://doi.org/10.1115/1.4034576

165. S. Murad, J. Murad, H. Khan, A smarter SMA technology for the realization of drug delivering endoscopic capsule, Rawal Med. J. 38 (2013) 66-74. 